\title{
Die Stadt Rom als triumphaler Raum und ideologischer Rahmen in der Kaiserzeit
}

\begin{abstract}
Since the Roman state began in middle-republican times to expand to a Great Power of the Mediterranean, the public spaces of the city of Rome were shaped into stages of political memory and used for ritual manifestations of military rule and imperial ideology. The article deals with triumphal spaces of Rome as structured places of interaction between public architecture and political actors; regarding the power of the emperor the leading question concerns the interrelation between dynamic change and static stability. The investigation is conducted on three levels: first, the practice of public building with allocated roles of the emperor, the senate and other actors, transforming the cityscape into a stage of the omnipresent imperial victor; second, the practice of public actions and rituals within the spaces of triumphal architecture, creating vital experiences of imperial rule; third, the gradual change of public architecture from memorials of dynamic history to the 'eternal' presence of universal power, and the transformation of the triumph procession from a testimony of a specific glorious event to an obligatory biographical ritual that every new emperor was expected to perform. As a consequence, the question is raised whether Max Weber's three types of legitimate rule should be complemented by a forth type of 'ideological rule'.
\end{abstract}

\section{Dynamik und Statik als Kategorien historischer Machtbildung}

Die Bedeutung des römischen Triumphrituals in der Kaiserzeit, so haben die Initiatoren dieses Bandes zu Recht festgestellt, ist in der Forschung verkannt worden, weil die Triumphe der Kaiser nicht den Erwartungen entsprachen, die die Historiker an Phänomene von historischer Bedeutung gestellt haben. Dabei geht es zum einen um die Formen: Kaiserliche Triumphe, so das gängige Urteil, seien zu einem monotonen Spektakel verkommen und stellten darum eine inhaltsleere Fortführung einer Tradition dar, die ihre eigentliche vitale Entwicklung in der Republik gehabt habe. Zum anderen, aber damit zusammenhängend, geht es um die politischen Inhalte: Unter

\footnotetext{
Ich danke Fabian Goldbeck und Johannes Wienand herzlich für gründliche, kritische und hilfreiche Lektüre des Beitrags: womit ich nicht beanspruche, dass sie mit allen hier vertretenen Ansichten einverstanden sind. - Manche der folgenden Überlegungen gehen von früheren eigenen Arbeiten aus. Daher die indezente Zahl von Selbst-Zitaten.
} 


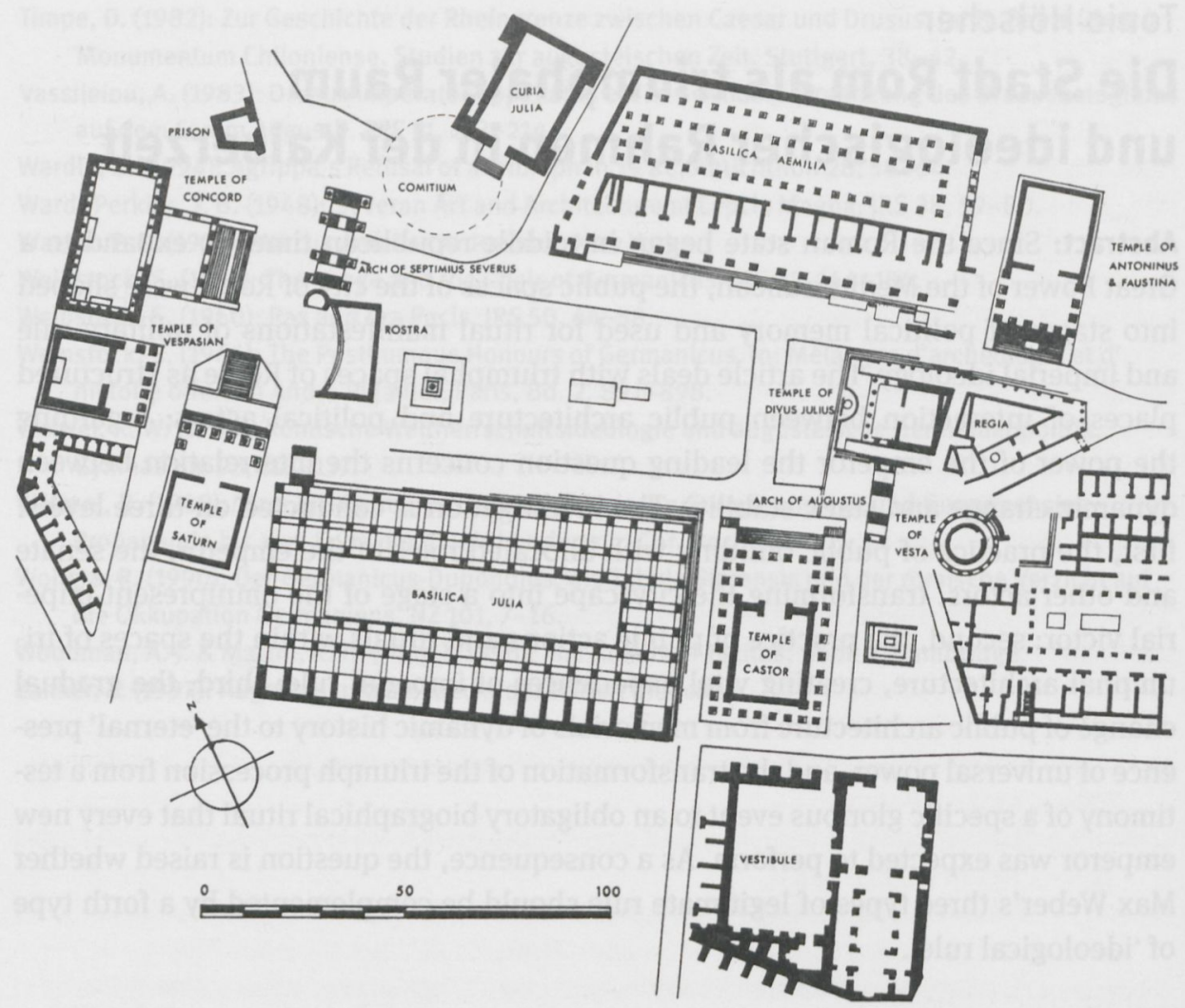

Abb. 9.1: Forum Romanum zur Zeit des Augustus. Nach: F. Sear, Roman Architecture (1989) fig. 27.

den Vorgaben der Alleinherrschaft sei der Triumphzug ein für die Machtverhältnisse irrelevantes Zeremoniell geworden, das kein zentrales historisches Interesse verdiene.

Die Gegenposition, die ein angemesseneres Verständnis der Phänomene einleiten soll, geht zu Recht grundsätzlich von der Tatsache aus, dass in den literarischen, epigraphischen und bildlichen Zeugnissen den Triumphen der Kaiser eine außerordentliche Bedeutung beigemessen wird. Im Besonderen stellt sie überzeugend die beiden genannten Ansichten und Ansätze in Frage: Triumphzüge der Kaiserzeit weisen formal in der Tat eine beträchtliche Vielfalt der zeremoniellen Realisierung auf; und sie entfalten inhaltlich in dem heute aktuellen Verständnis des römischen Kaisertums als einer ,Herrschaft ohne Verfassung ein beträchtliches politisches Potential für die Begründung von Macht.

Ich will diesen gut begründeten Positionen nicht widersprechen, will sie aber durch eine komplementäre Position ergänzen: Der römische Triumph der Kaiserzeit besitzt neben einem gewissen Potential der okkasionellen Veränderung durchaus stark konstante Züge - und gerade darin besteht ein großer Teil seiner Stärke und Bedeutung. Das heißt, das das Defizit des traditionellen Verständnisses des kaiser- 
zeitlichen Triumphes nicht nur in der Verkennung seiner Dynamik, sondern vor allem auch in der Missachtung des historischen Potentials seiner Statik besteht. Als Historiker - und darin sind Archäologen selbstverständlich eingeschlossen - haben wir gelernt, Geschichte als Wandel zu sehen, historische Kräfte nach ihrem Potential der Veränderung zu messen und die Bedeutung historischer Personen und Gruppen nach ihrer Individualität, ihrer Differenz gegenüber Vergangenheit und Umwelt zu beurteilen. Dagegen besitzen wir kein vergleichbares Instrumentarium, um Konstanz und Statik in ihrer geschichtlichen Bedeutung zu verstehen. Das Triumphritual der römischen Kaiserzeit scheint ein guter Anlass zu sein, diese Positionen zu überdenken.

Damit soll gewiss nicht das Rad wieder in die Gegenrichtung zurückgedreht werden. Worum es geht, ist: Dynamik und Statik des Triumphs gegeneinander aufzurechnen und sie zueinander ins Verhältnis zu setzen. Ohne Zweifel sind die Triumphzüge der Kaiserzeit von einer gewissen Veränderungsdynamik geprägt - dabei muss dann genauer gefragt werden, die weit die Veränderungen das Ritual als solches betreffen oder aber ihren historischen Kontext, die Umstände der betreffenden Feldzüge und die politische Situation in Rom. Wenn dagegen im Folgenden die statischen Elemente besonders stark betont werden, so zum einen deshalb, weil sie die größeren Schwierigkeiten für ein angemessenes historisches Verständnis zu bieten scheinen, zum anderen, weil ein bisher wenig beachteter Faktor, die triumphalen Räume, diese Perspektive nahe legt.

\section{Öffentliche Räume als Bühne der Macht}

Rom als ,triumphaler Raum‘: Was ist das? Und was impliziert es? Ein Beispiel mag das Spektrum der Phänomene und Fragen beleuchten, die mit dem Begriff zusammenhängen (vgl. Abb. 9.1).

Nach der Schlacht von Actium, also zum Zeitpunkt der Begründung seiner Alleinherrschaft, weihte Octavian an der Ostseite des Forums in Rom den Tempel für seinen Adoptivvater, den Divus Iulius. Das Kultbild stellte Caesar in priesterlichem Habit mit dem Lituus des militärischen auspiciums dar, ein umlaufender Fries weist mit Victorien, die aus Ranken wachsen, auf Caesars Sieghaftigkeit als Grundlage einer neuen Glückszeit hin. Vor der Fassade war das Tempelpodium als Rednertribüne gestaltet, an der erbeutete Rostra der Flotte des Antonius und der Kleopatra angebracht waren. Octavian schloss damit den Gründungssieg seiner Herrschaft an die Siege seines vergöttlichten Vaters an. Zu Seiten des Tempels aber wurden vom Senat zwei Ehrenbögen für Octavian/Augustus errichtet, die seine Siege feierten: einer für Actium, ein zweiter für den Erfolg gegen die Parther. Beide Bögen trugen Standbilder des Princeps in einer triumphalen Quadriga, der zweite Bogen war außerdem wahrscheinlich mit den Fasti der Konsuln und der Triumphatoren geschmückt, die von den Anfängen Roms bis zu Augustus als Ziel der römischen Geschichte führten. Die Ostseite des 
Forums hatte mit dem Tempel und den Ehrendenkmälern eine repräsentative Fassade erhalten, die wie ein Bild die einzigartige Stellung des neuen siegreichen Herrschers dokumentierte. Die übrigen Seiten des Platzes wurden entsprechend umgestaltet. ${ }^{1}$

Doch der Begriff der ,Repräsentation' ist nicht ausreichend: Das Konzept des ,öffentlichen Raumes` enthält mehr als die bildhafte Wirkung der Architektur: Es schließt die Akteure, das heißt die Initiatoren, Nutzer und Betrachter, und ihre Aktionen und Verhaltensweisen ein. Neuere Konzepte des kulturellen Raumes haben zu einem neuen Verständnis von Architektur und Urbanistik geführt, das über die traditionellen statischen Begriffe des ,Stadtbildes' und der ,Repräsentation' hinausführt. Kulturelle Räume entstehen durch soziales Handeln, das den vorgefundenen Elementen des Raumes Bedeutung zuweist, den Raum durch neu geschaffene Elemente bedeutungsvoll gestaltet und durch sinn-gesteuerte Aktionen Menschen, Architekturen und natürliche Umwelt zueinander in Beziehung setzt. ${ }^{2}$

Zunächst die Initiatoren der Architektur. Der Tempel war nach Caesars Tod von den Triumvirn gelobt und dann von Octavian allein eingeweiht worden. Neben den Kultstätten verschiedener Gottheiten am Forum war das eine ungeheuerliche Vereinnahmung des Zentrums der Stadt durch den neuen Prätendenten der Alleinherrschaft: ein massiver Akt eines durchgesetzten Machtanspruchs. Die Bögen dagegen waren vom Senat und Volk errichtet: architektonisch als Beitrag zu dem Gestaltungswillen des Princeps, politisch als Ehrung und Zustimmung der Bürgergemeinschaft zu seinem Anspruch. Das ist eine konzertierte Rollenverteilung, die auch für die anderen Bauten des Forums und darüber hinaus für die ganze Stadt gilt: Augustus tritt nicht als urbanistischer Allein-Akteur auf, sondern errichtet das neue Rom in einer gemeinsamen Aktion zusammen mit Senat, Rittern und Volk, den Vertretern der großen republikanischen Familien, seinen politischen Gefolgsleuten, den früheren Anhängern des Antonius, Mitgliedern des Ritterstandes, den Berufs-Kollegien und schließlich den Mitgliedern seiner eigenen Familie. Es ist eine reziproke Praxis des Konsenses: Der Herrscher setzt für die Gemeinschaft Akzente, die Gemeinschaft antwortet darauf und legitimiert ihn in seiner Machtstellung. Diese aktionale Bedeutung der Architektur ist allerdings am stärksten im Akt der Entstehung: Im Lauf der Zeit tritt der interaktive Charakter der Bauten zurück, und sie schließen sich zu einer homogenen Kulisse des Prinzipats zusammen. ${ }^{3}$

Sodann die Benutzer: zunächst die offiziellen Akteure. Die Kaiser und andere Exponenten der res publica benutzten den Raum vor den Gebäuden für ihre Auftritte. Tiberius hielt von der Rednertribüne vor dem Tempel seine Laudatio auf den verstor-

1 Im Einzelnen ist hier vieles, vor allem die Identifizierung und Lage der Bogenmonumente, umstritten. S. dazu Zanker 1972: 12-17; Coarelli 1985: 258-324; Nedergaard 1993; Freyberger 2009: 58-70. Das letzte Wort ist hier noch nicht gesprochen.

2 Sozialer Raum: Lefebvre 1974; Delitz 2009; Muth 2014.

3 Allgemein s. dazu unten S. $304 \mathrm{f}$. 
benen Augustus, Traian verkündete von dort seine Schenkungen an das römische Volk. Vor dem Podium befand sich eine weitere Tribüne, auf der die Praetoren Recht sprachen, ebenfalls mit dem Tempel des Divus Iulius im Hintergrund. ${ }^{4}$

Die realen Protagonisten wurden ergänzt durch ideale Akteure. In dem Tempel waren die Götter und in den Denkmälern die Kaiser konzeptionell präsent. Alles was in den Räumen vor den Fassaden geschah, wurde im Bezug auf die Gottheit bzw. den Gründer des Prinzipats und auf deren ideologische Bedeutung vollzogen. Tiberius bei seiner Rede auf Augustus ebenso wie Traian bei der Verkündigung seiner Schenkung, und auch der Praetor bei der Rechtsprechung agierten im Angesicht des Divus Iulius; wahrscheinlich wurden bei solchen Gelegenheiten, wie bei religiösen Festen, sogar die Türen des Tempels geöffnet, um einen unmittelbaren Sichtkontakt zwischen dem Kultbild und dem Staatsakt herzustellen. Spätere Triumphatoren zogen durch die Ehrenbögen des Augustus in das Forum ein, wie lebende Abbilder des ersten kaiserlichen Triumphators. ${ }^{5}$

Schließlich das Publikum. Seit Augustus galt eine Verordnung, dass das Forum nur in der feierlichen Staatstoga betreten werden durfte, die ihre Träger zugleich zu gemessenen und würdigen Verhaltensformen zwang. Bei Staatsakten wurden Bevölkerung und Militär auf dem Forum nach sozialem Rang aufgestellt; dabei erhielt das Militär Plätze vor den Tempeln, deren Gottheiten für das Wohl und die Sicherheit der res publica zuständig waren. Damit waren nicht nur die führenden Staatsmänner, sondern alle Benutzer und Besucher des Forums in die aktive Konstituierung des öffentlichen Raumes eingebunden. ${ }^{6}$

Kurzum: Die öffentlichen Räume Roms waren weit mehr als der gängige Begriff des ,Stadtbildes“ suggeriert: Es waren Räume der Interaktion zwischen den wichtigsten konzeptionellen Akteuren der res publica: den politischen Protagonisten, den Göttern und dem Volk. Das gilt insbesondere auch für die ,Triumphalen Räume‘. In den Aktionen und Interaktionen entfalteten die Räume eine ungemein starke semantische Bedeutung und Wirkung.

\section{,Triumphale Topographie‘: Elemente und Synthese}

Die ,Triumphale Topographie‘ der Stadt Rom wurde durch verschiedene Bauten, Denkmäler und andere Elemente konstituiert, die jeweils verschiedene Funktionen im öffentlichen Leben Roms erfüllten. Dabei besteht eine Grundvoraussetzung des kaiserzeitlichen Triumphs darin, dass die triumphalen Räume in der Grundstruk-

4 Tiberius: Suet. Aug. 10o. Traian: s. die sog. Anaglypha Traiani: Torelli 1982: 89-118.

5 S. dazu Hölscher 2006b.

6 Toga auf dem Forum: Suet. Aug. 40. Staatsakte auf dem Forum: unten S. 303. 
tur bereits in der Republik ihre Gestalt erhalten hatten. Die Forschung ist allzu sehr gewohnt, die Wirklichkeit historischer Epochen ausschließlich aus deren eigenen zeitgenössischen Manifestationen zu rekonstruieren; Bauwerke, Denkmäler und Stadtbilder werden nach Intention und Wirkung zur Zeit ihrer Entstehung untersucht. Doch ein großer Teil der materiellen Lebenswelt, insbesondere der städtischen Lebensräume, bestand damals wie heute in Bauten und Anlagen, die aus langen Vergangenheiten vorhanden waren und Maßstäbe setzten. Gerade beim Triumph bewegte man sich ständig zwischen einer prägenden Vergangenheit und einer aktuellen Gegenwart.

\section{Tempel und Denkmäler für militärische Siege}

Die triumphale Topographie Roms war vor allem durch Tempelbauten und öffentliche Denkmäler geprägt. In beiden Gattungen sind aufschlussreiche Veränderungen der ,triumphalen Praxis‘ zwischen Republik und Kaiserzeit deutlich (vgl. Karte 1 und Karte 5).

Seit der ersten expansiven Phase Roms im späteren 4. und 3. Jahrhundert v. Chr. pflegten die römischen Feldherren Tempel für die Götter zu geloben und zu errichten, denen sie ihre Siege verdankten. In der Regel waren das Gottheiten, die in einem weiteren Sinn mit den militärischen Erfolgen zu tun hatten: entweder Spezialgötter wie Iuppiter Stator und die Tempestates, denen für ihr Eingreifen in die Schlacht gedankt wurde, oder Gottheiten politischer Begriffe, wie Victoria, Fides, Spes, Virtus, Honos und Pietas, deren Wirken dabei honoriert wurde. Ein großer Teil der Neubauten von Tempeln in der mittleren und späten Republik sind derartige Siegestempel. Sie repräsentierten die wichtigsten Leitbilder des mos maiorum, der in dieser Epoche als Maxime der politischen Führungsschicht ausgebildet wurde. ${ }^{7}$

Gegenüber diesen einzelnen Manifestationen von Sieg und Triumph tat Augustus nun einen entscheidenden Schritt: Indem er gleich zu Beginn seiner Herrschaft innerhalb eines Jahres insgesamt 82 Tempel der Hauptstadt restaurieren ließ, machte er sich vor allem das ganze Panorama von Siegeskulten der Expansion zu einem Weltreich aus der Republik zu eigen. Einige dieser Tempel, deren Gottheiten ihm besonders nahe standen, wie Apollo, Mars und Neptunus, verband er mit der eigenen Person, indem er sie am eigenen Geburtstag oder an anderen Gedenktagen seiner Laufbahn neu dedizierte und ihnen damit ,kaiserliche‘ Festtage gab. ${ }^{8}$ Darüber hinaus schlossen Augustus mit dem Tempel für Mars Ultor und Vespasian mit dem Templum Pacis an die republikanische Tradition an und stellten ihre triumphalen Siege in den

7 Hölscher 1978: 349; Hölkeskamp 1987/22011: 238-240; Pietilä-Castren 1987; Ziolkowski 1992; Orlin 1997; Walter 2004: 131-154, zu den Tempeln 134-136; Itgenshorst 2005: 89-147.

8 Gros 1976: 31-36. 


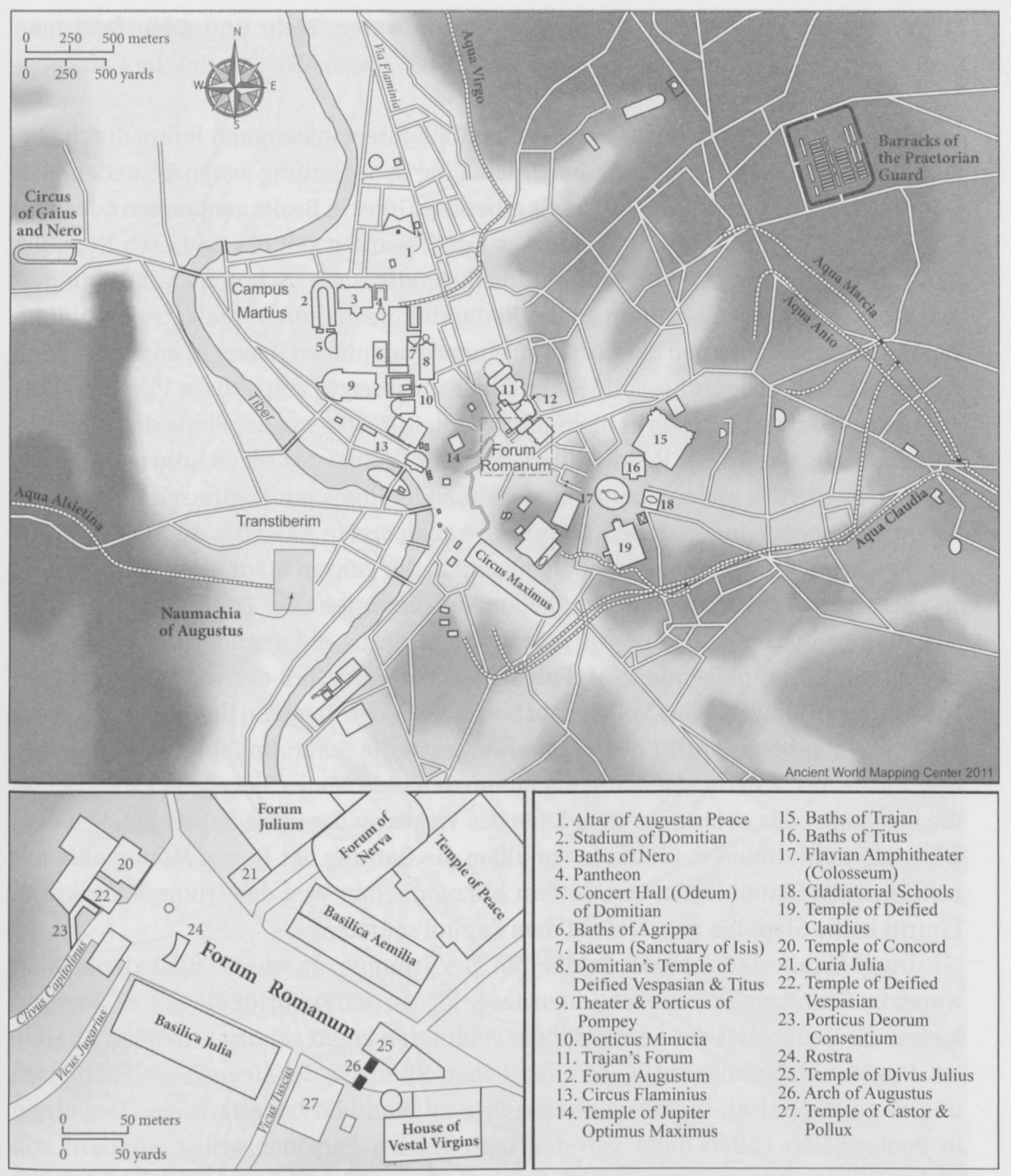

Karte 5: Rom beim Tod Trajans (117 n. Chr.)

zentralen öffentlichen Räumen der Stadt als Fundament ihrer Herrschaft vor Augen. Auffallend ist allerdings, dass dieser Zusammenhang zwischen Triumph und Siegestempel in der Kaiserzeit immer lockerer wurde: Schon von Claudius ist kein Tempel nach seinem Britannien-Sieg bekannt, auch Traian errichtete nach den Daker-Kriegen keinen Tempel, eben so wenig wie Marc Aurel nach den Markomannen-Kriegen. Wahrscheinlich waren die großen Kriegsrituale Roms so stark an die Tempel des Iuppiter Optimus Maximus und des Mars Ultor gebunden, dass für neue Siegestempel 
keine sinnvollen Funktionen mehr einzurichten waren. Mehr und mehr fand man andere Formen der Verstetigung von Siegen: Das Traians-Forum und die CaracallaThermen feiern Siege ohne Tempel.

Daneben gaben die Feldherren der Republik ihrem ephemeren Ruhm durch permanente Denkmäler dauerhaften Ausdruck. Eine neue Gattung waren Beutedenkmäler: Während nach traditioneller Praxis erbeutete Güter in Besitz genommen oder dem Staatsschatz zugeführt und umgenutzt wurden, wurden seit der mittleren Republik Beutestücke denkmalartig in der Öffentlichkeit aufgestellt: Schon im 4. Jahrhundert machten die Rostra von Antium an der Rednerbühne und die vergoldeten Samnitenschilde über den Tabernen das Forum zu einem triumphalen Raum. In anderen Fällen wurde Beute in bedeutungsvolle Standbilder umgesetzt. ${ }^{9}$ Auch diese Praxis weitete Augustus massiv aus, indem er nicht nur erbeutete Rostra von der Flotte des Antonius und der Kleopatra an der Rednerbühne vor dem Tempel des Divus Iulius anbrachte, sondern auch viele andere Bauten und Denkmäler Roms mit Rostra schmückte, von einem Ehrenbogen für die Erneuerung der Straßen bis zur Basis des Apollo Palatinus; der Sieg bei Actium war mit diesen Symbolen in der ganzen Stadt präsent. ${ }^{10}$

Besonders provozierend waren Denkmäler, die entlang des Triumphweges errichtet wurden, in kompetitivem, oft polemischem Bezug aufeinander (vgl. Abb. 9.2). Bereits 264 v. Chr. präsentierte M. Fulvius Flaccus einen Teil der von ihm geraubten 2000 Bronze-Bildwerke aus Volsinii auf Sockeln vor den Tempeln der Fortuna und der Mater Matuta, beim Eintritt des Triumphweges in die Stadt; im Jahr darauf konterte sein Rivale Mn. Valerius Messalla mit einem Gemälde seines Sieges über Hieron und die Karthager, das er kurz vor dem Ende des Weges an der Curia anbrachte. Seit dem frühen 2. Jahrhundert v. Chr. kam vor allem die Gattung der Bogen-Monumente mit bekrönenden Standbildern von Göttern hinzu, die den Weg des Triumphzuges vom Eintritt in die Stadt bis zum Ziel auf dem Kapitol säumten. ${ }^{11}$

Diese Manifestationen der Feldherren, der Triumphzug wie die Beutedenkmäler, waren im Grundzug Dokumentationen der Feldzüge und Dank für die Götter. Dagegen hatten die Denkmäler des Senats für die Feldherren einen explizit ehrenden Charakter. Das gilt insbesondere für die öffentlichen Bildnisse der siegreichen Feldherren und dann der Kaiser, die die zentralen Orte im Stadtbild beherrschten. Sie wurden in den meisten Fällen nicht von den betreffenden Personen selbst, sondern von anderen Instanzen zu deren Ruhm errichtet. Die größte Ehre war, wenn der Senat ihre Verdienste und ihre Ausnahmestellung durch permanente Präsenz im Bild in

9 Hölscher 1978: 318-3200.

10 Cass. Dio 51.21-22. Hölscher: 1985: 83-87; Fähndrich 2005: 233.

11 Zum Weg des Triumphzuges als symbolischer Raum bereitet Sven Schipporeit eine ausführliche Untersuchung vor. S. vorläufig Schipporeit 2008; La Rocca 2008. Beutedenkmäler des M. Fulvius Flaccus: Torelli 1968. Gemälde des Mn. Valerius Messalla: Plin. Nat. hist. 35.22. Bogen-Denkmäler der Republik: De Maria 1988: 262-266, n. 49-54. 


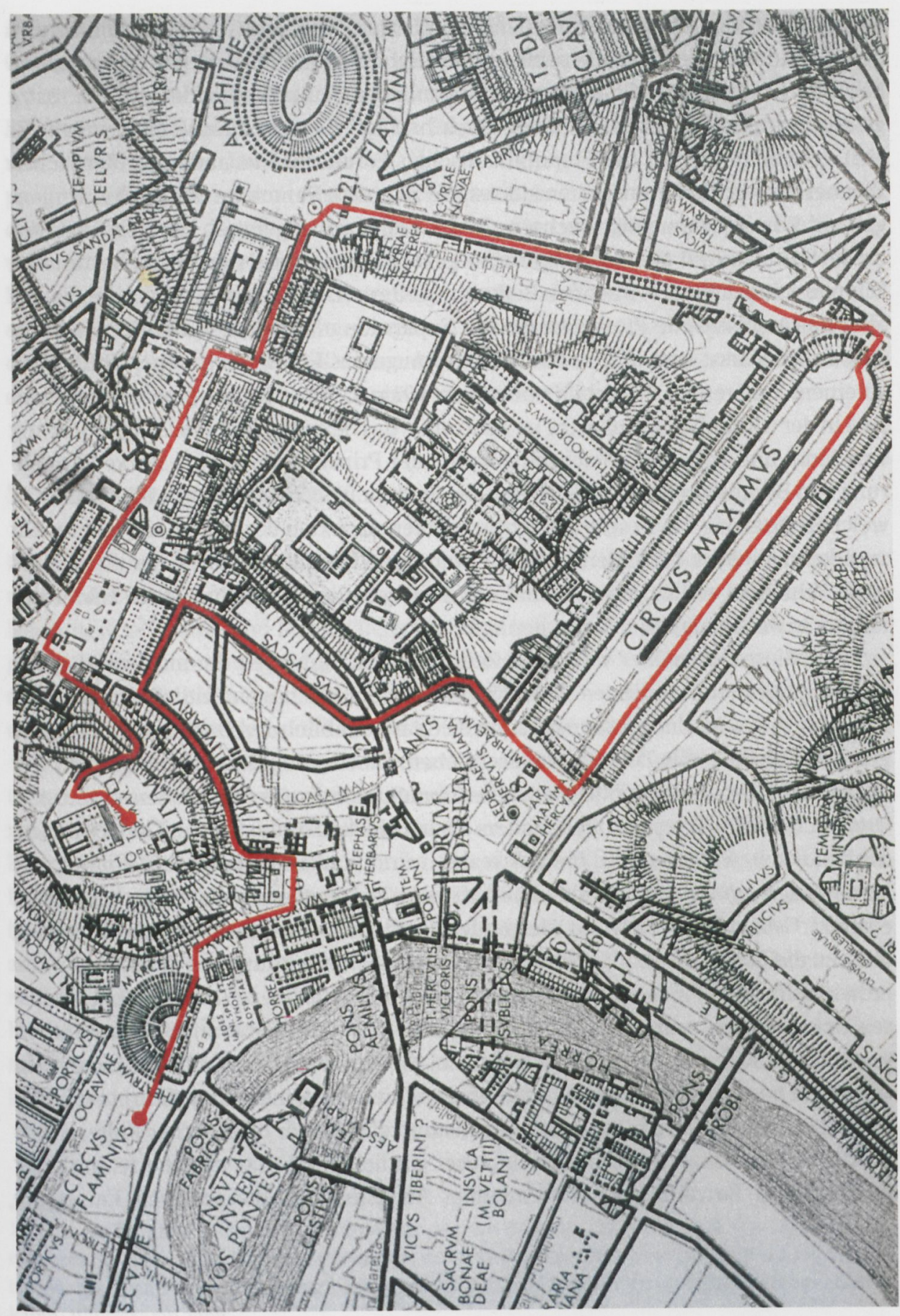

Abb. 9.2: Rom, Stadtzentrum: Route des Triumphweges (Hubert Vögele, Heidelberg). 
den Räumen des öffentlichen Lebens anerkannte, vor allem auf dem Forum und dem Comitium. Spezifische Typen von Bildnisstatuen und Ehrendenkmälern stellten besondere militärische Qualitäten vor Augen, etwa Säulendenkmäler, z.T. mit rostra geschmückt, oder Reiterstandbilder. Auch hier hat Augustus die Vergangenheit für sich vereinnahmt. Auf dem republikanischen Forum und in anderen öffentlichen Räumen waren die Ehrenstatuen sukzessive zu einem Panorama der großen Vergangenheit Roms zusammengewachsen. In der Kaiserzeit scheint es hier seit Augustus zu Selektionen und Systematisierungen gekommen zu sein, die diesen Bestand an Bildnissen nach ihrer bleibenden Bedeutung filterten. Auf dem eigenen neuen Forum aber hat Augustus die Protagonisten der Expansion als Vorläufer der eigenen Siege zusammengefasst und in den Portiken des Augustus-Forums mit neuen Bildnissen zu einem kohärenten Schaubild von summi viri zusammengeführt, mit dem eigenen Bild in der triumphalen Quadriga im Zentrum - das bezeichnenderweise eine Stiftung von Senat und Volk war. Gleichzeitig wurde der Princeps durch eine starke Vermehrung von Bildnisstatuen in allen Teilen der Stadt präsent gemacht. Wie häufig und an welchen Orten sie ihn in spezifisch triumphalen Aspekten darstellten, ist nicht mehr zu erkennen. Aber besonders markant waren die Bogendenkmäler, die aus Anlass eines Triumphs errichtet waren und die im Wesentlichen als Sockel für Bilder des Kaisers in der Triumphquadriga dienten. ${ }^{12}$

Alle diese Denkmäler waren zur Zeit ihrer Errichtung seit der mittleren Republik einmalige Manifestationen in der Konkurrenz der mächtigen Feldherren und ihrer Familien gewesen. Und dieser okkasionelle Charakter blieb den Denkmälern in einem gewissen Maß für alle Zukunft eingeschrieben. Die Ehrenbildnisse hielten nicht nur individuelle Personen, sondern auch bestimmte historische Situationen vor Augen. Und auch an den Tempeln blieb, anders als in Griechenland, stets das Gedächtnis an die historischen Männer und Ereignisse der Gründung haften. Rom wurde damit, wie keine andere antike Stadt, zunehmend zu einer kommemorativen Landschaft seiner eigenen Geschichte. Doch mit steigendem zeitlichem Abstand von der Gründung müssen die Aspekte der sukzessiven Manifestationen von Ruhm und des Kampfes um individuelle Macht sich mehr und mehr verschliffen haben, und die Tempel schlossen sich zu einem zunehmend homogenen urbanistischen Panorama all der Gottheiten und ideologischen Konzepte zusammen, die die kollektive Macht des römischen Imperium begründeten. Sie alle hatten ihren Platz nebeneinander in dem staatlichen Festkalender und waren insgesamt Gegenstand simultaner öffentlicher Kulte, durch die die Gemeinschaft der Bürger sich dieser göttlichen Mächte versicherte. In dieser tendentiellen Entzeitlichung übernahmen Augustus und die späteren Kaiser die

12 Ehrenstatuen der Republik: Hölscher 1978: 324-344; Sehlmeyer 1999; Papini 2004. - Summi viri auf dem Forum Augusti: Spannagel 1999: 256-358. - Bildnisse des Augustus: Boschung 1993. 
religiös-ideologische Topographie der Stadt, als einen ideologischen Raum, in dem Gegenwart und Vergangenheit ineinander aufgehoben waren. ${ }^{13}$

Auf die massive Ausweitung der triumphalen Präsenz des Kaisers antwortete die Bevölkerung im Bereich ihrer Wohnsitze. Repräsentative Häuser konnten nach außen mit Stirnziegeln geschmückt werden, die die Siegesgöttin Victoria mit einem Tropaeum zeigten, oft auf dem Globus der Weltherrschaft stehend oder von capricorni, dem Sternzeichen des Augustus, flankiert. Für die Innenräume stellten Bildhauerwerkstätten Schmuckreliefs zum Einlassen in die Wände her, die Victoria mit Symbolen von Seesiegen zeigten. An beweglichen Gegenständen gab es ein Spektrum von einfachen Tonlampen über Fingerringe mit Gemmen und Glaspasten bis zu - allerdings seltenen - vornehmen Kameen und Silbergefäßen mit triumphalen Motiven, die eine diffuse ,triumphale ${ }^{\text {‘ }}$ Atmosphäre verbreiteten. ${ }^{14}$

\section{Strukturierung der Räume}

Die Verteilung der spezifisch ,triumphalen Räume in der Topographie von Rom wirkt auf den ersten Blick diffus, zeigt aber deutliche Schwerpunkte. Eine besondere Häufung von Bauten und Denkmälern für Siege liegt an den konzeptionellen Angelpunkten des Triumphweges (vgl. Abb. 9.2): am Eingang in die Stadt um die Porta Triumphalis, im Zentrum um das Forum und am Ziel auf dem Kapitol. Dabei weisen die einzelnen Gattungen charakteristische Konzentrationen auf. ${ }^{15}$

Tempel, die nach Siegen geweiht wurden, finden sich über das Stadtgebiet verteilt, mit besonderer Dichte aber im Bereich des rituellen Eingangs des Triumphzuges, der Porta Triumphalis: außerhalb des Pomeriums die Tempel des Apollo und der Bellona, mit der columna bellica für das Ritual der Eröffnung des Krieges; dazu die Kultbauten von Feldherren um den Circus Flaminius und am Forum Boarium; innerhalb der Mauer mehrere Tempel um das Forum Boarium. Auf dem Weg des Triumphzuges war dies - nachdem das Forum und das Kapitol bereits mit politischen und religiösen Bauten ausgestattet waren - der Raum, in dem sich die besten Gelegenheiten boten, das spektakuläre Ritual mit einer imposanten und bedeutungsvollen religiösen Kulisse zu rahmen. Ähnliche, wenngleich nicht ganz so dichte Eingangsbereiche mit Siegesmonumenten wurden an anderen wichtigen Zugängen der Stadt

13 Rom als Erinnerungsraum: Walter 2004: 131-154, zur Entzeitlichung s. 132 und 139: „Anfangs Monumente des politischen Wettbewerbs wurden sie (d. h. die Denkmäler) erst sekundär zu Haltepunkten der geschichtlichen Erinnerung“. Itgenshorst 2005: 89-147; dazu die Beiträge bei Stein-Hölkeskamp, Hölkeskamp 2006.

14 Hölscher 1985: 89-102; Maderna-Lauter 1988.

15 S. dazu vorläufig Hölscher 2001. Zum Triumphweg s. die Arbeiten von E. La Rocca und S. Schipporeit: oben Anm. 11. 
geschaffen: um die Porta Capena, dem Zugang von Süden über die Via Appia, und entlang der Via Flaminia, dem Zugang von Norden. ${ }^{16}$

Ehrenstatuen für siegreiche Feldherren dagegen sind vor allem im Bereich des Forums konzentriert. Die ersten Standbilder, für C. Maenius und F. Camillus, wurden am Comitium errichtet; andere folgten an bedeutungsvollen Orten des Forums: etwa das Reiterstandbild des Q. Marcius Tremulus beim Tempel der Reiterpatrone Castor und Pollux, oder das hochragende Säulendenkmal des C. Duilius im Zentrum des Platzes. Hier dienten die Bildnisse der Protagonisten der römischen Expansion als Vorbilder für alle politischen Aktivitäten und Entscheidungen von Senat und Volk. ${ }^{17}$

Auf dem Kapitol dagegen häuften sich Beuteweihungen an Iuppiter Optimus Maximus, den obersten Gott aller Siege, dem das abschließende Opfer des Triumphrituals dargebracht wurde. Die geweihten Rüstungen und Waffen wurden im Lauf der Zeit so zahlreich, dass schon um die Mitte des 2. Jahrhunderts v. Chr. eine erste ,Säuberung' vorgenommen werden musste. ${ }^{18}$

Auf den ganzen Weg des Triumphzuges wurden die Bogenmonumente verteilt. In republikanischer Zeit waren sämtliche fornices von Feldherren mit Bildern von Gottheiten auf die Prozession bezogen, in der Kaiserzeit sind schon außerhalb der Mauer Bögen für Germanicus, Tiberius, Domitian, Hadrian, innerhalb der Porta triumphalis zwei für Titus und einer für Konstantin, um das Forum für verschiedene Kaiser von Augustus bis Septimius Severus und auf dem Kapitol für Nero und Traian bezeugt. Hinzu kamen Bogenmonumente über anderen Zugangsstraßen, vor allem der Via Appia und der Via Flaminia. ${ }^{19}$

Eine neue Praxis der Kaiserzeit bestand dann darin, dass die Herrscher neue öffentliche Räume schufen, die zwar im wesentlichen nicht ,triumphalen` Funktionen dienten, die aber von einer kohärenten ,triumphalen‘ Ideologie durchdrungen waren (vgl. Abb. 9.3). Insbesondere die kaiserlichen Forumsanlagen inszenierten die Macht des Herrschers auf militärischer Grundlage. Das Augustus-Forum war dem Mars Ultor geweiht, in den Portiken repräsentierten die Porträts der republikanischen Staatsmänner vor allem die kriegerische Erfolgsgeschichte Roms, und im Zentrum stand der Kaiser selbst auf einer triumphalen Quadriga, umgeben von den Personifikationen der Provinzen des Reiches. Ähnliches gilt für das Traians-Forum, das aus der Beute der Daker-Kriege finanziert war und in dem Standbilder der Offiziere, Feldzeichen der beteiligten Legionen, dekorative Friese mit Sieges-Symbolen und der bildliche Kriegsbericht der Säule sich zu einem vielstimmigen Triumph-Konzert für den kaiserlichen Sieger zusammenschlossen. Selbst das Templum Pacis des Vespasian mit seinen Rosen-Rabatten und den Meisterwerken griechischer Bildkunst, die aus der Domus

16 S. dazu Coarelli 1988; Coarelli 1997: 363-538.

17 Sehlmeyer 1999: 45-141; Papini 2004: 147-205.

18 Reusser 1993: 46.

19 De Maria 1988: 262-325, n. 49-104. 


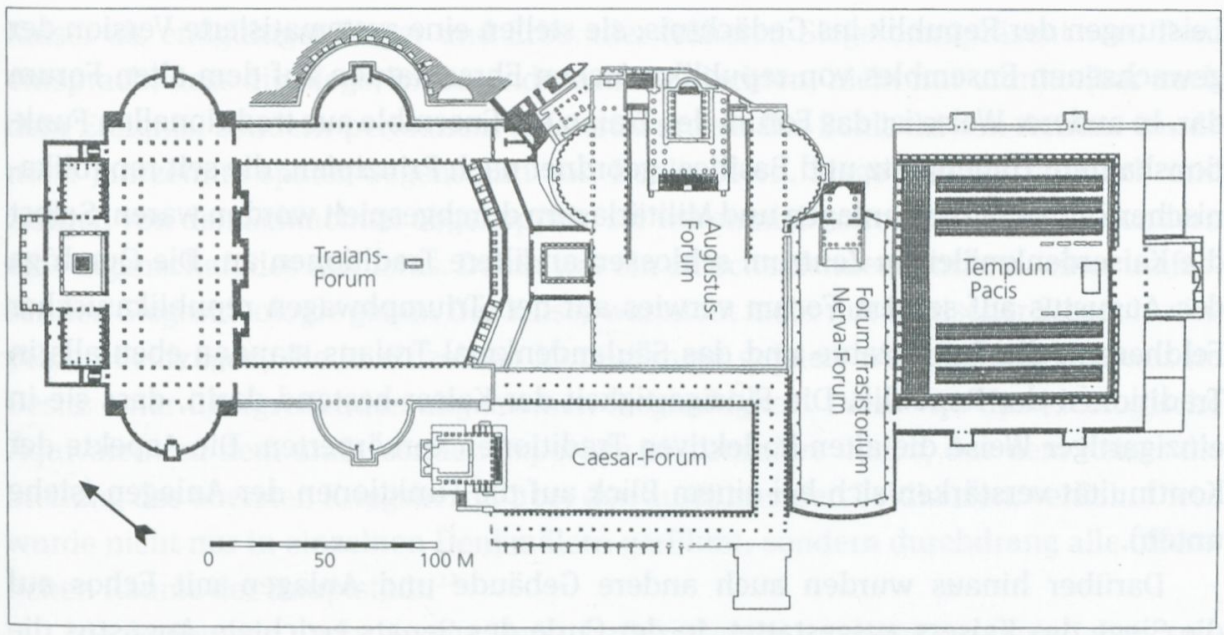

Abb. 9.3: Rom, Kaiserfora. Nach: T. Hölscher, Klassische Archäologie, Grundwissen (2015) Abb. 38.

Aurea Neros hier dem Volk wiedergegeben wurden, war kein Kunstmuseum, sondern ein Kosmos der Weltherrschaft: mit Darstellungen der archetypischen Siege Alexanders des Großen gegen die Perser und der Pergamener gegen die Kelten, Bildern des Nils und der Skylla als Zeichen der Macht über ferne Länder und Meere, und so fort. ${ }^{20}$

Diese kaiserlichen Anlagen stellten, gegenüber den triumphalen Tempeln und Denkmälern der Republik, spektakuläre neue Räume im Stadtbild von Rom dar: in ungleich größeren Dimensionen, mit einheitlicher Planung und visueller Beziehung aller Elemente zueinander. Es waren massive Eingriffe in das Konzept der Stadt, die jeweils neue Gravitationszentren im gesamten urbanistischen Gefüge bildeten und damit die einzigartige Macht des betreffenden Kaisers vor Augen führten. Und diese Manifestationen unterschieden sich auch konzeptionell voneinander. Auf Schlagworte vereinfacht: Augustus setzt sich mit seinem Forum ins Verhältnis zur Tradition der Republik, Vespasian antwortet mit dem öffentlichen Garten des Templum Pacis auf Neros Domus Aurea, Traian setzt mit seinem Forum so stark wie keiner seiner Vorgänger auf die eigene Leistung von Kaiser und Heer, auf die Effizienz einer neuen Verwaltungselite - und kann dabei sogar auf den bisher selbstverständlichen Kult einer Gottheit verzichten. Jede dieser Anlagen muss neu und einzigartig gewirkt haben.

Und doch ist die starke Verbindung mit Traditionen der Republik nicht zu übersehen. Das Forum des Augustus war ex manubiis errichtet wie die republikanischen Siegestempel. Im Plan und Konzept schließt es eng an republikanische Tempelplätze wie die Porticus Metelli an. Die Galerien von Bildstatuen rufen die großen Männer und

20 Augustus-Forum: Zanker 1970; Spannagel 1999. - Traians-Forum: Zanker 1970. - Templum Pacis: Bravi 2012: 167-181. - Neue Grabungen und Forschungen: La Rocca 2001. 
Leistungen der Republik ins Gedächtnis; sie stellen eine systematisierte Version der gewachsenen Ensembles von republikanischen Ehrenstatuen auf dem alten Forum dar. In anderer Weise ist das Forum des Traian ein Ensemble aus traditionellen Funktionsbauten: Hallenplatz und Basilica, geordnet nach Prinzipien, die seit republikanischer Zeit an Forumsanlagen und Militärlagern durchgespielt worden waren. Selbst die Kaiserdenkmäler im Zentrum schlossen an ältere Traditionen an: Die Quadriga des Augustus auf seinem Forum verwies auf den Triumphwagen republikanischer Feldherren, die Reiterstatue und das Säulendenkmal Traians standen ebenfalls in Traditionen der Republik. Die Einzigartigkeit der Kaiser bestand darin, dass sie in einzigartiger Weise die alten kollektiven Traditionen verkörperten. Die Aspekte der Kontinuität verstärken sich bei einem Blick auf die Funktionen der Anlagen (siehe unten).

Darüber hinaus wurden auch andere Gebäude und Anlagen mit Echos auf die Siege des Kaisers ausgestattet. In der Curie des Senats errichtete Augustus die berühmte Statue der Victoria auf dem Globus, die die Beratungen des hohen Gremiums unter das Motto der Weltherrschaft stellte. Das Mausoleum des Augustus und die vorgelagerte Sonnenuhr enthielten ägyptische Obelisken, die den Sieg über Kleopatra als Grundlage seiner Macht einschärften. Nicht zuletzt waren die Unterhaltungsstätten der Volksmassen symbolische Räume der umfassenden römischen Weltmacht: Im Circus Maximus stellte Augustus einen Obelisken auf, unter dem die Wettrennen zu einem archetypischen Kampf um den Sieg wurden; hinzu kamen eine Zählmaschine mit Delphinen als Zeichen der Seeherrschaft und mindestens eine Statue der Victoria auf einer Säule. Im Colosseum, das von Vespasian aus der Beute des Jüdischen Krieges errichtet wurde, nahmen die Gladiatorenspiele und Jagden auf exotische Tiere den Charakter vernichtender Kämpfe gegen die Mächte der Fremdheit, des Unrechts und der Wildnis an. ${ }^{21}$

Die vornehmsten dieser Orte und Räume von Sieg und Triumph stammten aus der Vergangenheit der Republik und hielten die großen Ereignisse, Taten und Tugenden der römischen Geschichte präsent. Die Kaiser haben diese triumphale Topographie nur partiell weiter entwickelt. Im Wesentlichen haben sie die vorgefundene Topographie übernommen, sie prächtiger ausgebaut, sich darin bewegt und sie auf diese Weise aktuell gemacht.

Insgesamt aber stellten die triumphalen Räume in der Kaiserzeit doch eine grundsätzlich neue Situation dar. Während die Feldherren der Republik jeweils mit einzelnen Bauten oder Denkmälern einzelne triumphale Orte schufen, die dann im Lauf der Zeit zu triumphalen Räumen zusammenwuchsen, hat unter Augustus die konzertierte Aktion der urbanistischen Erneuerung Roms dazu geführt, dass die ganze Stadt zu einem gegliederten triumphalen Gesamtraum zusammengefasst wurde, in dem der

21 Victoria in der Curia: Hölscher 1967: 6-47. - Obelisken am Mausoleum des Augustus: von Hesberg/Panciera 1994: 32-33. - Circus Maximus: Humphrey 1986 - Colosseum: Alföldy 1995. 
Kaiser als endgültiger Sieger und Erbe aller früheren Siege omnipräsent war. Dem entsprach, dass die Siege, insbesondere die Schlachten, nicht nur unmittelbar nach dem Ereignis, sondern permanent gefeiert wurden: Die Schlacht von Actium wurde noch Jahrzehnte später Gegenstand von Denkmälern. Siege wurden räumlich und zeitlich von den Schlachten abgekoppelt, sie waren nicht nur eine Leistung, sondern eine Eigenschaft des Augustus. Damit war ein entscheidender Schritt zu einer umfassenden Siegesideologie getan: Der Kaiser war nicht mehr nur faktischer Sieger in einzelnen Feldzügen, die in einzelnen Monumenten gefeiert wurden, sondern war im Besitz einer übergreifenden allgemeinen Sieghaftigkeit. Diese war das ideologische Äquivalent zu dem umfassenden imperium proconsulare maius, das dem Kaiser die Stellung des obersten Kriegsherrn, über den ausführenden Feldherren, verlieh. Diese wurde nicht nur in einzelnen Denkmälern gerühmt, sondern durchdrang alle öffentlichen Räume der Hauptstadt. ${ }^{22}$

Ideologien von umfassenden Herrschaftssystemen tendieren zu räumlicher, zeitlicher und thematischer Universalität. Seit dem frühen 1. Jahrhundert v. Chr. brachten die großen Feldherren der Republik in ihren Denkmälern zunehmend den Anspruch zum Ausdruck, die römische Herrschaft bis an die ,Grenzen der Welt' im Norden und Süden bzw. Osten und Westen auszudehnen. Marius errichtete in Rom komplementäre Monumente für seine Siege über die Germanen im Norden und Jugurtha im Süden; Sulla, Pompeius und Caesar übertrafen sich mit Tropaia bei Chaironeia im Osten, in den Pyrenäen im Westen und bei Zela in Kleinasien; in der Hauptstadt selbst wetteiferten Pompeius und Caesar mit spektakulären Kunstwerken aus exotischen Materialien: Pompeius zeigte in seinem Triumph ein Bildnis von sich aus Perlen vom Roten Meer, Caesar weihte im Tempel der Venus einen Brustpanzer von Perlen aus Britannien. $^{23}$

Eine umfassende Präsenz der siegreichen Herrschaft Roms im ganzen Reich wurde jedoch erst in der frühen Kaiserzeit erreicht. Ein weit gespanntes geographisches Konzept wird in Bogenmonumenten für Augustus im Auftrag des Senats deutlich, die die wichtigsten Überlandstraßen, nicht zuletzt für die Bewegung von Heeren, an ihrem Anfang in Rom und ihrem Ende bei einem der Überseehäfen markierten: die Via Appia und ihre Fortsetzungen wurden 30 v. Chr. am Forum Romanum und in Brundisium, die Via Flaminia 27 v. Chr. am Pons Mulvius und in Ariminium mit Ehrenbögen ausgestattet. Noch ambitiöser und systematischer waren die Ehrenbögen, die für Germanicus nach seinem Tod beschlossen wurden: in Rom beim Circus Flaminius, in

22 Dauerhaftigkeit des Sieges seit Caesar und Augustus: Hölscher 1967: 150-156, 157-164; Fears 1981. 23 Tropaea des Marius: Prop. 3.11.46; Vell. Pat. 2.43.4; Val. Max. 2.2.3, 2.5.6, 4.4.8, 6.9.14; Suet. Aug. 6.1. - Sulla: Plut. Sulla 19.9-10; Paus. 9.40.7. Camp 1992. - Pompeius: Sall. Hist. 3.89; Strab. 3.4.1-9, 4.1.3. Castellvi/Nolla/Rodá 1995. - Caesar: Cass. Dio 40.48.2. - Bildnis des Pompeius aus Perlen vom Roten Meer: Plin. Nat. hist. 37.14-16. - Panzer Caesars aus Perlen von Britannien: Plin. Nat. hist. 9.116; Plut. Caes. 23.3; Cass. Dio 39.53.2. Hölscher 2004: 95-96. 
Germanien bei Mainz und in Syrien. Darüber hinaus haben Städte im Reich den Sieg von Actium und die Rückführung der signa von den Parthern mit Denkmälern gefeiert, die die Begründung einer neuen Zeit überall präsent machten. Die Konzepte und Maßnahmen der Hauptstadt und des Imperiums ergänzten einander. ${ }^{24}$

\section{Triumphale Räume und rituelle Praxis}

Was bedeuten diese Phänomene für das Verständnis des Triumphs in der politischen Praxis der Kaiserzeit? Entscheidend ist, in welcher Weise sich die triumphalen Manifestationen in die Wirklichkeit des Lebens einprägten.

Der Triumphzug, als einmaliges Spektakel, rief starke Emotionen hervor und blieb auf diese Weise in Erinnerung. Dabei beruhte die Wirkung auf der performativen Präsenz der Teilnehmer an der Prozession und auf der Partizipation der Zuschauer. Dasselbe gilt für die ephemeren Veranstaltungen von Gastmählern, Theater- und Circusspielen, die kollektive Hochstimmung und mehr oder minder bleibende Dankbarkeit an den Stifter hervorriefen. Im Gegensatz zu diesen emotionalen Events appellierten die rühmenden Denkmäler des Senats für den Triumphator wie die Beutestiftungen des Feldherrn dauerhaft an die visuelle Anschauung und sicherten ein unzerstörbares Gedächtnis. Auch sie aber waren Teil und Faktoren der Lebenspraxis. Die Bedeutung der triumphalen Räume, mit ihren Sakralbauten und Denkmälern, bestand, über ihre bildhafte, repräsentative Präsenz hinaus, in den Handlungen, aus denen sie entstanden und die sie generierten. In diesem Sinn bedürfen die statischen Elemente der öffentlichen Räume der Dynamisierung in menschlichen Aktionen.

\section{Bauten und Denkmäler als Aktion}

Die Errichtung von öffentlichen Anlagen, religiösen Bauten und politischen Denkmälern war stets ein Akt, der zwischen den politischen und gesellschaftlichen Akteuren ausgehandelt wurde. Die Akteure bedienten sich verschiedener Medien, die zueinander ins Verhältnis gesetzt wurden. Dabei wurde die Praxis grundsätzlich von eingespielten Strukturen und Regeln geleitet, die im einzelnen Fall entweder bestätigt oder auch überdehnt und modifiziert, selten aber völlig gesprengt wurden. Die Fragen, die sich dabei ergeben, sind: Wer gestaltete die triumphalen Räume? Wer gab die Denkmäler in Auftrag? Wer profitierte davon in welchem Sinn? Wie agierte und reagierte

24 Bogendenkmäler Forum und Brundisium: De Maria 1988: 236 Anm. 8, 267-268 Anm. 56. Pons Mulvius und Ariminum: De Maria 1988: 269 Anm. 58, 260-262 Anm. 48. Actium und Parther-Erfolg: Schäfer 1998; Zachos 2001. 
die Gemeinschaft gegenüber den Protagonisten? Wie änderten sich die Praktiken bei Veränderung der politischen Grundsituationen?

Seit der mittleren Republik war die Konstituierung triumphaler Räume, wie oben dargelegt, eine Sache der reziproken Balance zwischen der Gemeinschaft der Bürger, konzentriert im Senat, und den führenden Feldherren: Der Senat gewährte dem Feldherrn Anerkennung durch die ephemere Ehre des Triumphs und die dauerhafte Auszeichnung durch eine Ehrenstatue, der Feldherr seinerseits gab den Sieg gewissermaßen durch Schenkungen und Stiftungen an die Gemeinschaft zurück. In der späten Republik wurde diese Balance mehr und mehr aufgekündigt durch die exzessiven Ansprüche der großen Heerführer, die mit gezielten Provokationen und Transgressionen ihre Kraft des Durchsetzens gegenüber dem Senat erprobten und demonstrierten - bis Augustus diese Praxis umdrehte. Seitdem spielte der Senat die Rolle, dem Kaiser extreme Ehren anzutragen, und dieser konnte sie dann, je nach seiner Auffassung von der Stellung des Herrschers, mehr oder minder stark reduzieren. Diese Praxis wird besonders deutlich bei der Gründung des Pantheon und der Ara Pacis eingespielt. Beim Pantheon, einer Stiftung des Agrippa, bestand zunächst der Plan, eine Bildnisstatue des Augustus im Inneren des Baues unter den Bildern der Götter aufzustellen; diese hohe Ehrung hat Augustus abgelehnt, und man fand die Lösung, dass Augustus und Agrippa Statuen in der Vorhalle erhielten. Vierzehn Jahre später, als Augustus aus Gallien und Spanien zurückkehrte, trug der Senat ihm höchste Ehren an, darunter einen Altar in der Curia für seine Rückkehr und persönliche Asylkraft gegenüber allen, die sich innerhalb des Pomeriums in seinen Schutz begaben; wieder lehnte Augustus ab, und man einigte sich auf einen monumentalen Altar für die Göttin des von ihm gesicherten Friedens, die Ara Pacis Augustae. Es wäre sicher falsch, in beiden Fällen Kommunikationsschwierigkeiten oder gar gegensätzliche Auffassungen zu erkennen, die man besser im Voraus im kleinen Kreis gelöst hätte: Es sind öffentliche Akte der Bestimmung der Rolle des Kaisers. Eben so verfehlt wäre es, hier eine reine Inszenierung einer republikanischen Fassade zu sehen, da der Kaiser ja doch die Fäden in der Hand gehabt habe: Denn die Form, die Praxis der verteilten Rollen, ist entscheidend: In dieser Form wurde die Macht ausgehandelt und praktiziert. Die damit erreichte Balance entsprach in mancher Hinsicht wieder mehr der Situation der mittleren Republik, aber die antithetische Dialektik der Rollen von Herrscher und Gemeinschaft war ungleich pointierter geworden. ${ }^{25}$

Diese Rollen werden gerade in jenen öffentlichen Anlagen der Hauptstadt deutlich, die militärische Herrschaft, Siege und Triumphe zum Thema haben. Sie sind durchweg als konzertierte Aktionen entstanden: Der Kaiser stiftete und baute für das ,Volk،, aber Senat und Volk ehrten ihn dafür. Unmittelbar nach dem Sieg gegen Antonius weihte Octavian das von ihm errichtete Senatsgebäude, die Curia Iulia ein, stattete sie mit einer Statue und einem Altar für Victoria aus, und gab damit die von ihm

25 Cass. Dio 53.27.2-4, 54.25.3. Hölscher 2000: 247-259. 
errungene Weltherrschaft Roms an den Senat zurück; Senat und Volk aber ehrten den Princeps am selben Ort mit dem goldenen Ehrenschild, auf dem seine vier Kardinaltugenden virtus, clementia, iustitia und pietas gerühmt wurden. Später errichtete Augustus den Tempel des Mars Ultor, ein Votiv für seine frühen Siege, im Rahmen eines Forums mit sehr weiten politischen und juristischen Funktionen, aber das Monument im Zentrum zu seinen Ehren, das den Kaiser in einer triumphalen Quadriga darstellte, war eine Stiftung von Senat und Volk. Traian baute nach den Dakerkriegen die größte aller Forumsanlagen zum Nutzen der Bevölkerung und rühmte in der bildlichen Ausstattung die siegreichen Legionen und verdienten Offiziere, doch wieder wurden die zentralen Denkmäler für den Kaiser selbst, eine Reiterstatue auf dem vorderen Platz und die Säule mit seinem Bildnis im rückwärtigen Hof, vom Senat und Volk errichtet. Die Säule wurde sogar in einem eigenen Akt, ein halbes Jahr nach dem Forum, eingeweiht, sicher nicht weil sie nicht rechtzeitig fertig geworden wäre, sondern um den Akt der Ehrung des Kaisers von dem der kaiserlichen Stiftung zu trennen und als Antwort der Gemeinschaft auf seine Wohltaten erscheinen zu lassen. ${ }^{26}$

Alle Denkmäler der expliziten Rühmung des Kaisers sind nicht von ihm selbst zum eigenen Ruhm, sondern von anderen Instanzen als Ehrung errichtet worden, in Rom selbst vor allem von Senat und Volk, im ganzen Reich aber auch von einer Vielzahl weiterer Institutionen, Gruppen und Personen, von Provinzen, Städten, Corporationen, Amtsträgern, bis hin zu Privatpersonen. Das gilt insbesondere für die große Zahl der Kaiserbildnisse, aber auch insbesondere für die Bogenmonumente, die zum Ruhm des kaiserlichen Triumphators errichtet wurden. Hier wird der Wandel von der Republik zur Kaiserzeit besonders deutlich, er scheint sogar terminologisch zum Ausdruck gebracht worden zu sein: Die republikanischen Bögen, fornix/fornices genannt, waren von den Feldherren selbst gestiftet, sie trugen Bilder von Göttern; dagegen wurden die Bögen der Kaiserzeit vom Senat und Volk zu Ehren des Herrschers errichtet, dessen Bildnis auf einer Quadriga sie trugen. In einem Herrschaftssystem, das auf Konsens basierte, konnte es nicht anders sein: Rühmung und Anerkennung des Herrschers musste von außen kommen. ${ }^{27}$

Die öffentliche, auch die ,triumphale‘ Repräsentation des Kaisers in Denkmälern ist darum nicht adäquat mit dem häufig gebrauchten Begriff der ,Selbstdarstellung“ zu erfassen. In der Regel handelt es sich um Manifestationen von Konsens. Es soll nicht geleugnet werden, dass dabei ein mehr oder minder starker allgemeiner Erwartungsdruck vom Kaiser ausging, aber damit ist die Praxis nicht ausreichend erklärt: Entscheidend war auch hier die äußere Form der verteilten Rollen. Der Senat hatte zwar nicht mehr die Kontrolle über die Macht, aber er machte seine Zustimmung als entscheidenden Faktor sichtbar. ${ }^{28}$

26 Victoria und clupeus virtutis: Hölscher 1967: 6-17, 102-112.

27 Grundsätzlich: Mayer 2002: 5-18; Dally 2007; von den Hoff 2009.

28 S. zur Terminologie Bergmann 2000, die den Begriff der ,Repräsentation vorzieht. 
Diese Praxis war auch in der Kaiserzeit noch stark von der jeweiligen okkasionellen Situation geprägt. Wiederum ist es allerdings deutlich, dass mit fortschreitender Zeit der Charakter als Zeugnis einer bestimmten historischen Situation mehr und mehr in der Weiternutzung aufgehoben wurde. Auch diese Denkmäler wurden zu einem sich sukzessiv ergänzenden, aber simultan wahrzunehmenden Panorama kaiserlicher Herrschaft und Größe.

\section{Bauten und Denkmäler in Aktion}

Nach der Fertigstellung und Dedizierung waren die triumphalen Bauten und Denkmäler nicht stumme Zeugen der Vergangenheit, sondern prägende Faktoren des öffentlichen Lebens. Bauwerke und Denkmäler stellten das einmalige Ereignis des Sieges auf Dauer. Sie machten das Ereignis über räumliche und zeitliche Distanzen in der Mitte der Gesellschaft präsent. Sie gaben den Mitgliedern der Gesellschaft einen Anstoß und die Möglichkeit, diese Ereignisse und ihre Protagonisten in ihr Leben einzubeziehen und mit ihnen umzugehen.

Das Ritual des Triumphs und andere Manifestationen siegreicher Macht entfalteten sich grundsätzlich in dem strukturierten Raum der Stadt: als Übergang zwischen Draußen und Drinnen, mit der Überschreitung der rituellen Stadtgrenze, der Umkreisung des Palatin, der Durchquerung des Forums, bis zum zentralen Kultplatz auf dem ,heiligen Berg', dem Kapitol (vgl. Abb. 9.2): Dabei waren jene ,triumphalen Räume‘ von besonderer Bedeutung, die am stärksten mit Monumenten geschmückt waren: der Bereich um die Porta Triumphalis als Ort des Durchgangs, Circus Maximus und Forum als Orte der größten Sichtbarkeit für die Massen der Zuschauer, und das Kapitol als Bühne des abschließenden Opferrituals. Reliefs von kaiserlichen Staatsdenkmälern lassen erkennen, wie stark diese Vorgänge in Bezug auf die Architektur gesehen wurden. Der Einzug Marc Aurels auf dem Triumphwagen durch die Porta Triumphalis wird vor der Fassade des Tempels der Fortuna Redux geschildert, sein großes Siegesopfer vor der Kulisse des kapitolinischen Tempels in Szene gesetzt (vgl. Abb. 9.4). Die Gottheiten, Fortuna und Iuppiter, waren in ihren Tempeln anwesend und prägten durch diese konzeptionelle Präsenz die Räume des Rituals. Ähnliches gilt für die weiteren Tempel für göttliche Mächte des Sieges entlang des Parcours: Sie alle verkörperten die religiös-ideologischen Kräfte, die den Maßstab für den aktuellen Triumph darstellten. Der Triumphzug brachte die Tempel und Gottheiten, die er in das Ritual einbezog, zu aktueller Bedeutung. ${ }^{29}$

Auf dem Weg durch die Stadt passierte der Zug verschiedene Bogenmonumente früherer Triumphatoren. Wenn der siegreiche Kaiser auf seinem Viergespann durch

29 Hölscher 2006a. 


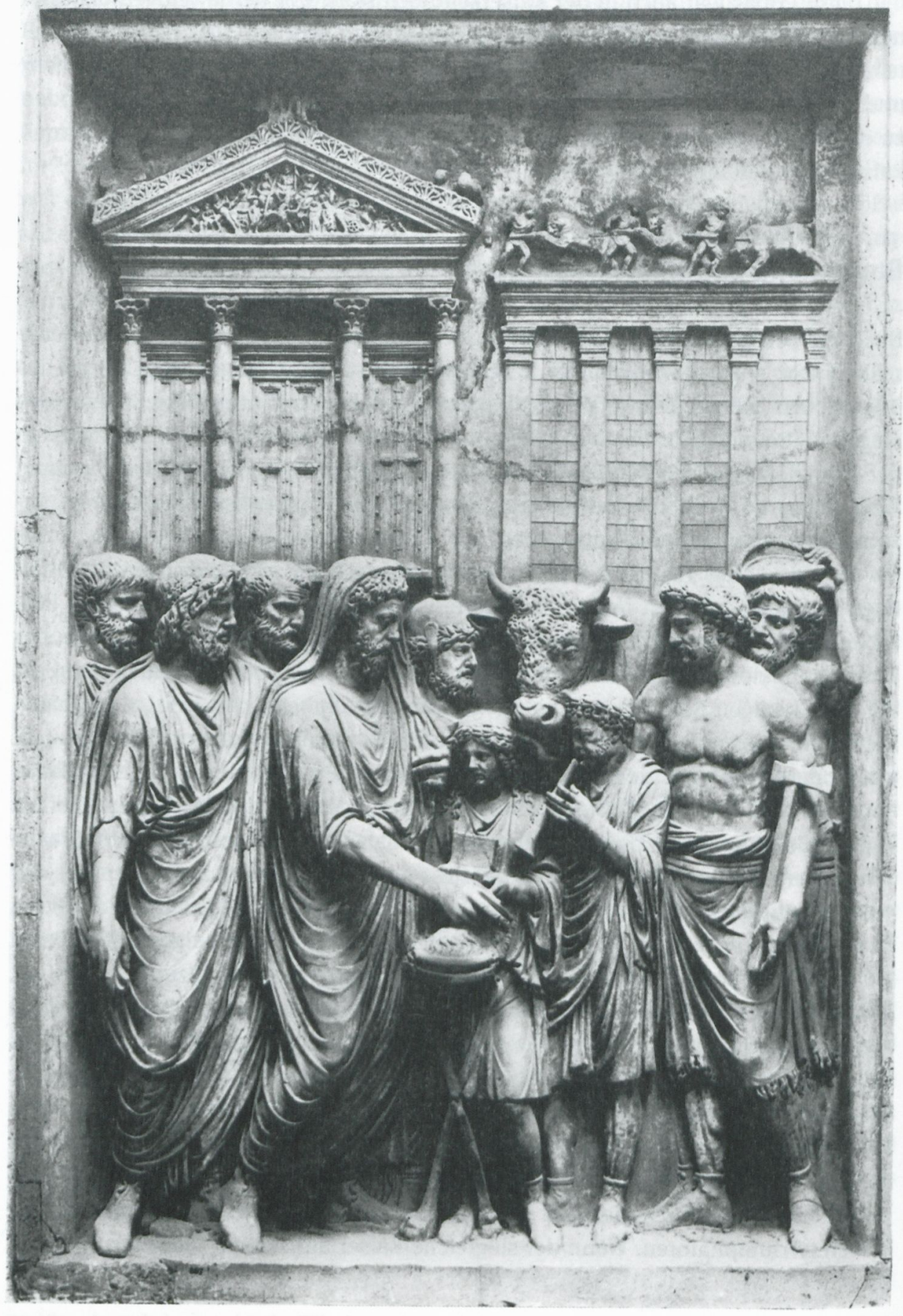

Abb. 9.4: Triumph-Opfer des Marc Aurel auf dem Kapitol. Rom, Palazzo dei Conservatori. Nach: I. Scott Ryberg, Panel Reliefs of Marcus Aurelius (1967) pl. XV. 
den Bogen fuhr, muss er für die Zuschauer als lebendes Abbild der goldbronzenen Quadriga seines Vorgängers über der Attika des Monuments erschienen sein.

Das Forum mit seinen vielen triumphalen Denkmälern stellte darüber hinaus einen vielfach nutzbaren Raum für andere Rituale von ,triumphalem`Charakter dar. Die Unterwerfung des Tiridates vor Nero wurde hier in einer spektakulären Zeremonie vor der Kulisse der Tempel, mit dem Kapitol im Hintergrund, in Szene gesetzt. Und die Begräbnisrituale der Kaiser wurden auf dem Forum als Beginn eines ,umgekehrten Triumphs' vom Zentrum zur Grabstätte außerhalb der Stadt begangen. ${ }^{30}$

Aber auch die weiteren ,triumphalen Räume، erhielten ihren Sinn erst in Handlungen der Nutzung. Vor allem die Tempel für Gottheiten des Sieges waren Orte des regelmäßigen staatlichen Kultes, bei dem die Gemeinschaft, kollektiv oder individuell partizipierend, Götter wie Iuppiter Stator oder göttliche Mächte wie Victoria und Fortuna, Fides, Virtus, Honos und Pietas verehren, sich ,zu eigen machen‘, und damit als verbindlich anerkennen konnte. In entsprechender Weise stellten die Ehrenbildnisse auf dem Comitium exemplarische Referenzgrößen für die Argumente und Entscheidungen bei den politischen Versammlungen von Senat und Volk dar: Man konnte sich auf die vorbildlichen res gestae und virtutes der großen Männer berufen, deren konzeptionelle Präsenz ebenso stark war wie die der Gottheiten in den Tempeln. ${ }^{31}$ Auch in dieser Nutzung liegt ein starkes Moment der Entzeitlichung: Die göttlichen Mächte wie die vorbildlichen Männer schlossen sich im Kult wie in der politischen Praxis zu einem Panorama verbindlicher Normen von überzeitlichem Charakter zusammen.

Aufschlussreich sind die triumphalen Forum-Anlagen der Kaiser (vgl. Abb. 9.3). Das Forum des Augustus, das in seiner Entstehung wie in seiner Ausstattung triumphale Aspekte vereinigte, sollte auch kriegerischen Funktionen dienen: Im Tempel des Mars Ultor sollte der Senat die Entscheidungen über neue Kriege und über die Verleihung des Triumphs an siegreiche Feldherren führen. Hier sollten triumphierende Feldherren Triumphalszepter und Lorbeerkranz weihen. Augustus deponierte hier die von den Parthern zurückgewonnenen Feldzeichen, spätere Feldherren stellten ausgewählte Beutestücke auf. Damit wurden zum Teil Funktionen, die seit alter Zeit im Tempel des Iuppiter auf dem Kapitol lokalisiert waren, auf das neue Zentrum des Augustus übertragen. Entsprechend wurden auch die rituellen Waffen des Kollegiums der Salier aus der Regia in den Tempel des Mars auf dem Augustus-Forum transferiert. Eigentlich allerdings war das neue städtische Zentrum für die Entlastung des alten Forums vor allem von den zunehmenden Aufgaben der Rechtsprechung geplant worden. Diese Aktivitäten fanden jedoch bezeichnenderweise im Rahmen und vor dem Hintergrund der ,triumphalen' militärischen Macht Roms in der Inszenierung in Bildern und Ritualen statt. Und diese Inszenierung hatte, als Fortsetzung

30 Unterwerfung des Tiridates: Suet. Nero 13. Kaiserliche Begräbnisfeiern: Zanker 2004.

31 Exemplarisch Hölkeskamp 2012. 
von rituellen Praktiken des Kapitols und der Regia aus republikanischer Zeit, einen starken Aspekt der Tradition und Kontinuität. ${ }^{32}$

Das Forum des Traian führt diese Entwicklung konsequent weiter. Die visuelle Ausstattung ist weit stärker als bei Augustus auf Präsentation militärischer Macht ausgerichtet, die Funktionen dagegen sind völlig auf zivile Akte konzentriert: Die Kaiser inszenieren vor der Kulisse des Kriegsruhmes Staatsakte wie Schuldenerlasse und Verteilungen von (Geld-) Geschenken, im Übrigen dient der weite Platz und die monumentale Basilica vor allem für Gerichtsverhandlungen, und in den angeschlossenen Bibliotheken entfaltet sich intellektuelles Leben. Die Rituale des Triumphs werden an den alten Orten und Räumen belassen. ${ }^{33}$

Insgesamt war die triumphale Ideologie in Rom, durch Architekturen und Rituale, im Gedächtnis und als Leitbild, so präsent und ubiquitär wie in wenigen anderen historischen Gesellschaften.

\section{,Ideologische Herrschaft' zwischen Norm und Realität}

\section{Normative Architektur}

Die ,triumphalen' Orte und Räume der Stadt Rom stellten einen relativ statischen Faktor in der Ausübung der kaiserlichen Herrschaft dar. Sie waren zum Teil in den Grundstrukturen der Stadt, mit Zentrum, Grenze und Peripherie, vorgegeben, teils seit republikanischer Zeit durch die Praxis der Errichtung von Siegestempeln und Denkmälern sukzessiv verfestigt - und durch neue Projekte nur sehr begrenzt erweiter- oder veränderbar. In dieser Form bildeten sie den Rahmen für die aktuelle Realität der kaiserlichen Triumphe. Das wirft schließlich die Frage nach dem Verhältnis von Statik und Dynamik, von Norm und spezifischer Realität auf, von der wir ausgegangen waren.

Die Inszenierung von Triumphzügen der Kaiserzeit hob stark auf die spezifischen Realitäten der einzelnen gefeierten Feldzüge und der eroberten Länder ab. Man gab sich große Mühe, die charakteristischen Leistungen der römischen Sieger, die exotischen Eigenarten der besiegten Völker und eroberten Länder, die physische Präsenz großer gefangener Gegner und die Einzigartigkeit der erbeuteten Schätze vor Augen zu führen. Selbst ein eher konventioneller Triumphzug wie der des Vespasian war nach der Beschreibung bei Flavius Josephus wie nach der Darstellung am Titus-Bogen ein

32 Funktionen des Augustus-Forums: Köb 2000: 225-268; Neudecker 2010.

33 Funktionen des Traians-Forums: Köb 2000: 283-304. 
einzigartiges, unwiederholbares Spektakel, mit sensationellen Schaustellungen der Siege und den Aufsehen erregenden Beutestücken aus dem Tempel von Jerusalem. Ganz zu schweigen von so exzentrischen Auftritten wie Caligulas Triumph über das Meer bei Puteoli und Neros Rückkehr aus Griechenland als musischer Triumphator. ${ }^{34}$

Dies alles spielte sich andererseits in einem relativ statischen Rahmen von ,triumphalen Räumen‘ ab. Wenn man diese Räume und ihre Elemente, die Bauten und Denkmäler, nicht nur als tote Kulissen, sondern als bedeutungsvoll-aktive Faktoren des politischen Lebens sieht, dann ergibt sich eine bezeichnende Dialektik zwischen Statik und Dynamik.

\section{Politische Ideologie und die Rituale des Kaisers}

Die Bauten und Denkmäler der triumphalen Räume repräsentierten einen Rahmen von ideologischen Normen und Erwartungen, die an die Tätigkeit des Kaisers gestellt wurden: virtus und honos, pietas und concordia, clementia und fides, fortuna, felicitas und aeternitas. Die Ideologie war nicht nur Interpretation und Bewältigung der vorausgegangenen realen Ereignisse, sondern vor allem auch Forderung an die Protagonisten für die Zukunft. Diese ideologischen Leitbilder der römischen Staatsmacht blieben während der Kaiserzeit weitgehend statisch in Geltung; dem entsprach ihre Fixierung in Kultbauten und Denkmälern und ihre Verankerung im Kalender der staatlichen Religion. Dem Kaiser seinerseits kam die Rolle zu, diese Normen in der spezifischen Realität der gegenwärtigen Situation umzusetzen. Diese Umsetzung der Leitbilder geschah natürlich zunächst in politischen Handlungen, doch ihre öffentliche Präsentation wurde in großen Ritualen vollzogen: virtus bei Profectio und Adventus und beim Triumph, pietas bei großen Staatsopfern, und so fort.

Dabei ließen die Normen und Erwartungen zwar einen gewissen Spielraum der Gestaltung: Zum einen entstanden durch die unterschiedlichen historischen Umstände, bei Kriegszügen wie in anderen Handlungsfeldern, spezifische Vorgaben, die nicht nur die effektiven Aktionen des Kaisers, sondern auch die rituellen Repräsentationen prägten; zum anderen, und vor allem, konnte der Kaiser seine Rolle in einer gewissen Spielbreite persönlich definieren: etwa mit mehr Nachdruck auf seiner eigenen virtus oder der von den Göttern geschenkten felicitas, auf dem tatsächlichen Sieg oder der dankbaren pietas für den Erfolg, auf einer Selbstdarstellung als griechischer Künstler oder als römischer Sittenwächter, auf einer Stellung als primus inter pares oder als übermächtiger Alleinherrscher. Darüber hinaus konnte es auch, unabhängig von einzelnen Kaisern, zu einem mittelfristigen Wandel kommen: So werden im späteren 2. und im 3. Jahrhundert n. Chr. die alten Leitbilder zu pauschalen Beschwörungen von immerwährendem Sieg und Glück gesteigert.

34 Triumph Vespasians: Schipporeit 2010. Caligula und Nero: s. unten S. 309. 
Die antiken Historiker, und offenbar allgemein die Zeitgenossen, haben die Herrschaft der einzelnen Kaiser sehr stark als von deren individuellen Charakteren geprägt gesehen. Man sprach von ,guten' und ,bösen‘ Herrschern, und jeder von ihnen war in anderer Weise ,gut‘ oder ,böse‘. Manche moderne Historiker folgen ihnen darin und sehen statt des ,Kaisertums“ als Institution nur einzelne Kaiser und ihre persönliche Auffassung der Herrschaft. Wie weit sie ,wirklich‘ so ,gut‘ oder ,böse‘ waren, kann zu Recht in Frage gestellt werden - aber auch das Urteil hat seine ,Wirklichkeit‘. Sofern die Zeitgenossen daran glaubten, muss diese Nahsicht ernst genommen werden.

Andererseits aber weisen aus einer distanzierteren Sicht viele Zeugnisse darauf hin, dass die individuellen Ausgestaltungen der Rolle des Herrschers nicht zu grundsätzlich gewertet werden sollten. Dabei handelt es sich vor allem um die Bilder der großen Staatsdenkmäler und der weit zirkulierenden Münzprägung. Man kann sich fragen, wie weit es berechtigt ist, das Bild dieser Medien als repräsentativ für die gesamte Auffassung der Herrschaft anzusehen. Gewiss kann es nicht darum gehen, die Unterschiede und die dynamischen Veränderungen der tatsächlich praktizierten Herrschaftsformen bei den verschiedenen Kaisern zu leugnen. Die Frage ist vielmehr, in welchem Verhältnis die relative Konstanz der Ideologie zu den Veränderungen der Herrschaftspraxis in den sich wandelnden Situationen und Verhältnissen der ,Realität‘ steht. In diesem Sinn ist zu fragen, welche Bedeutung es hat, dass die sich ständig ändernde Vielfalt der Manifestationen kaiserlicher Herrschaft in den Denkmälern und Bildwerken der öffentlichen Repräsentation immer wieder auf ein begrenztes und weitgehend dauerhaftes Spektrum von ideologischen Leitbildern reduziert wurde.

Die ideologischen Spielräume der einzelnen Kaiser waren offensichtlich insgesamt nicht sehr groß: Die Varianten waren immer auf einen einigermaßen festen Kanon von Normen bezogen. Die Leitbilder und ,Tugenden', aus denen die Kaiser ihre Rolle definieren konnten, hatten unter Augustus mit dem clupeus virtutis einen festen Kern erhalten. Auf Münzen erscheint das Spektrum zwar etwas erweitert, aber dabei relativ konstant; Veränderungen ergaben sich im Lauf der Jahrhunderte nur langsam und nicht so sehr als Neuerungen, sondern eher als Ausgestaltungen und Emphatisierungen des bestehenden Kanons. An monumentalen Staatsdenkmälern werden vielfach immer wieder dieselben Rituale dargestellt, in denen diese Leitbilder gefeiert werden. Es sind mehr oder minder dieselben Leitbilder, die auch in den Tempelbauten seit der Republik das Stadtbild prägten und in deren öffentlichen Kulten die Gemeinschaft diese Leitbilder bestätigte. ${ }^{35}$

$35 \mathrm{Zu}$ den Leitbildern auf den kaiserzeitlichen Münzen s. Noreña 2011, der stark auf die statistisch unterschiedlichen Aktualisierungen der, virtues' unter den einzelnen Kaisern abhebt. Aus einer etwas weiteren Perspektive ist es jedoch offensichtlich, dass es sich vor allem um variierende Selektionen aus einem relativ konstanten Repertoire handelt. $\mathrm{Zu}$ der hier vertretenen Auffassung s. Timpe 2011: 136-137: „Das Handeln der nach Charakter, Glück, Fähigkeiten, Dauer und historischer Bedeutung höchst unterschiedlichen kaiserlichen Persönlichkeiten variierte in konstitutioneller Hinsicht zwischen verhältnismäßig wenigen Verhaltensmustern und füllte insoweit trotz der farbigen Schicksale 
Die Differenzen zwischen den einzelnen Kaisern, die sich dabei ergaben, betreffen nicht so sehr den Kanon der Leitbilder als solchen, als vielmehr die Formen seiner Realisierung. Die Balance zwischen republikanischer Form und monarchischer Machtfülle, wie sie Augustus eingerichtet hatte, war zugleich sensibel und anstrengend. Vor allem im ersten Jahrhundert seiner Nachfolge versuchten darum bekanntlich verschiedene Kaiser, die Gewichte zu verschieben: zunächst Tiberius zurück zur Einbindung in die Senatsherrschaft, dann Caligula in die Gegenrichtung einer größeren Autonomie vom Senat. Und alle Kaiser, ob integrativ oder exzentrisch, strebten danach, die äußeren Formen der Herrschaft noch weiter zu steigern. Diese Unterschiede in der Herrschaftsauffassung waren vielfach entscheidend für Erfolg oder Misserfolg der einzelnen Herrscher. Im Grund aber entspringen diese Unterschiede wohl weniger einem - durch Erwartung und Druck von außen induzierten - Ideal der individuellen Profilbildung als solcher, als vielmehr einer tiefen Unsicherheit, in welchen Formen der Kaiser die gegenläufigen Anforderungen miteinander in Einklang bringen konnte: Denn letzten Endes scheiterten gerade die Kaiser, die am radikalsten auf distinktive Profilbildung setzten. Durchgehend aber blieben alle Herrscher, bei aller Verschiedenheit ihrer Herrschaftsformen, dem Kanon der ideologischen Leitbilder mit relativ begrenzten Varianten verpflichtet. Was sie anstrebten, war die ,einzigartige‘ Monopolisierung einer relativ statischen kollektiven Ideologie.

\section{Der Triumph als biographisches Ritual}

Der Triumph wurde bekanntlich von Augustus, und seitdem für alle Zeiten, auf den Kaiser und wenige Mitglieder des Kaiserhauses beschränkt. Zugleich mit dieser einschneidenden Maßnahme spielte sich eine Praxis ein, die eine weitere Steigerung der Ritualisierung bedeutete. Sie wird erkennbar, wenn man danach fragt, wann, wann nicht und wie oft die einzelnen Kaiser einen Triumph gefeiert haben. Das kann hier nur ganz holzschnittartig dargelegt werden.

Octavian/Augustus hat seinen einzigen - dreifachen - Triumph zu Beginn seiner Herrschaft 29 v. Chr. gefeiert, für Siege über die Dalmater, über Antonius und Kleopatra bei Actium sowie für die Eroberung von Ägypten. Mit der Dreizahl war eine gewisse Universalität der Herrschaft impliziert: europäischer Norden, griechischer Osten, afrikanischer Süden, in Konkurrenz zu Pompeius, der sich seiner Siege auf den drei Kontinenten Europa, Asien und Afrika rühmte. ${ }^{36}$ Diese Universalität der triumphal begründeten Herrschaft war als Konzept ,endgültig‘ und nicht mehr steiger-

der Imperatoren viel eher einen - durch das augusteische System und mit seiner Begründung - vorgegebenen Rahmen aus, als dass es diesen konstruktiv gestaltet und verändert hätte."Ich will auf diese Fragen an anderer Stelle zurückkommen.

36 Beard 2008: 7-41. 
bar: Danach hat Augustus bekanntlich keinen weiteren Triumph beansprucht, weder nach den Feldzügen in Spanien 26 v. Chr. (mit denen er der Weltherrschaft den Westen zufügte) noch nach dem ,Sieg، gegen die Parther 20 v. Chr., mit dem er die Herrschaft über den asiatischen Osten etablierte.

Augustus hat diese doppelte Regelung in demonstrativen Akten deutlich gemacht: Er zeigte seine Positionen auf, indem er Gegenpositionen öffentlich ablehnte. Vielleicht war schon nach dem Sieg von Actium seine Ablehnung des ihm angetragenen Beinamens Romulus und seine Zustimmung zu dem Namen Augustus mit dadurch bestimmt, dass er nicht wie der Stadtgründer als dauerhafter Triumphator erscheinen wollte. Jedenfalls hat er es 26 v. Chr. nach dem Feldzug in Spanien und offenbar auch 19 v. Chr. nach dem Parthererfolg zugelassen, dass der Senat ihm einen Triumph zusprach - um ihn dann nicht anzunehmen. 19 und 14 v. Chr. ließ er den Senat Triumphe für Agrippa nach dessen Feldzügen in Spanien und am Bosporos beschließen, die dieser ebenfalls ablehnte. 12 v. Chr. beschloss der Senat einen Triumph für Tiberius, dem wiederum Augustus sich widersetzte. Fünf Jahre später trug der Senat Augustus und Tiberius einen gemeinsamen Triumph an, den der Kaiser für sich selbst ablehnte, für Tiberius aber diesmal zuließ; dasselbe wiederholte sich im Jahr $19 \mathrm{n}$. Chr. Dies alles können gewiss nicht unkoordinierte Aktionen des Senats und kurzfristige Korrekturen durch den Kaiser sein: Denn zweifellos hätte man Meinungsverschiedenheiten in informellen Gesprächen ausräumen können. Es sind konsequent gesetzte öffentliche Zeichen. Vorschläge wurden in der Öffentlichkeit gemacht, Beschlüsse offiziell gefasst, um die Ablehnung zu einer expliziten öffentlichen Manifestation zu machen. Auf diese Weise stellte Augustus nacheinander klar, dass er selbst für Siege unter seinem imperium maius keine Triumphe mehr feiern würde, dass er eine strenge Beschränkung des Triumphes sogar gegenüber Mitgliedern des Kaiserhauses durchsetzen wollte, und dass er jedenfalls selbst über die Verleihung entscheiden wollte. ${ }^{37}$ Augustus' eigener dreifacher Triumph aber wurde dadurch, gewissermaßen in der Rückschau, zu einem Initiations-Ritual, mit dem er ein für alle Mal seine universale Sieghaftigkeit demonstrierte.

Tiberius feierte seine zwei Triumphe vor dem Antritt des Prinzipats: den ersten 7 v. Chr. als Anerkennung einer gewissen, aber nur temporären Position als zweiter Mann im Staat, bis zur Volljährigkeit der von Augustus adoptierten Enkel, den zweiten $12 \mathrm{n}$. Chr. zur Bestätigung seiner Rolle als designierter Thronfolger. Wie bei Augustus konnten die Erfolge in Germanien und Pannonien als Demonstrationen universaler Herrschaft in den beiden wichtigsten Feindes-Richtungen Nord und Ost verstanden werden. Auch dies waren Initiations-Triumphe, nach denen Tiberius während seiner

37 Beiname Romulus: Suet. Aug.7.2. - Alles weitere bei Itgenshorst 2008. Beschluss des Triumphs nach Parthererfolg: Schäfer 1998: 60 mit Anm. 60. - Beschluss und Ablehnung des Triumphs für Tiberius 12 v. Chr.: Suet. Tib. 9; Cass. Dio 54.31.3-4. 
Regierungszeit keine weiteren Feldzüge mehr übernahm und keinen Triumph mehr beging. ${ }^{38}$

Caligula strebte bald nach Regierungsbeginn, mit der Vorbereitung eines Feldzuges im Norden, militärischen Ruhm als Grundlage seiner Herrschaft an. Nach dem Scheitern der Unternehmungen in Germanien und gegen Britannien verzichtete er notgedrungen auf einen Triumph, ersetzte diesen dann aber durch den Super-Pseudo-Triumph bei Puteoli. Auch hier ist universale Herrschaft im Spiel: Mit der Überquerung des Meeres spielte er auf die intendierte Eroberung Britanniens an, zugleich brachte er als ,Beute‘ einen gefangenen parthischen Prinzen mit zurück. Nichts kann besser den Zwang belegen, sich früh in einem spektakulären Ritual als überwältigender Sieger zu präsentieren. ${ }^{39}$

Claudius nahm Caligulas Britannien-Projekt auf, sobald die Verhältnisse in Rom es zu erlauben schienen. Er beging seinen Triumph extrem früh, nachdem er ganze 16 Tage an dem Feldzug teilgenommen hatte - und obwohl der Krieg sich noch weitere acht Jahre hinziehen sollte. Britannien galt seit Caesar als finis terrae und konnte auch ohne östlichen Gegenpart die Herrschaft über den orbis terrarum bedeuten.

Der Osten meldete sich dann als neuer Erzfeind gleich nach dem Regierungsantritt Neros, als die Parther Armenien beanspruchten. Doch der Konflikt, mit Verhandlungen und Geiselstellungen, zog sich ohne einen triumphwürdigen Sieg in die Länge, und schließlich musste 66 n. Chr. die spektakuläre Unterwerfung des Tiridates vor dem Kaiser zum Ersatz dienen. Als Kompensation unternahm Nero, im unmittelbaren Anschluss daran, seinen Siegeszug durch die ,Schlachtfelder' der musischen Festspiele Griechenlands und feierte bei der Rückkehr nach Rom seinen extravaganten ,agonalen‘ Triumph. Universalität strebte er auf diesem Gebiet dadurch an, dass er in möglichst allen Kampfstätten in möglichst allen Disziplinen Siege erringen wollte. ${ }^{40}$

Geradezu ,perfekt‘ war der Herrschaftsantritt Vespasians, bei dem der Sieg über Iudaea, die Übernahme des Prinzipats und der Triumph unmittelbar aufeinander folgten. Für seinen Sohn Titus, der gleichberechtigt mit dem Vater den Triumph mitgefeiert hatte, war diese Manifestation des Siegesruhmes vor dem eigenen Regierungsantritt, wie für Tiberius, ausreichend.

Titus' Bruder Domitian aber hatte bei diesem Triumph eine untergeordnete Rolle gespielt und strebte darum schon früh nach militärischer Bewährung, die ihm jedoch während der Regierung seines Vaters und seines Bruders versagt wurde. Nach Titus' frühem Tod auf den Thron gelangt, suchte er darum sofort nach militärischer Legitimation, begann einen vielleicht nicht unbedingt nötigen Krieg gegen die germanischen Chatten und schloss ihn $83 \mathrm{n}$. Chr. mit einem Triumph ab, der offenbar von vielen als forçiert und eher dürftig bewertet wurde. Das mag der Grund gewesen sein,

38 Itgenshorst 2008. Zur Bedeutung des Triumphs von 7 v. Chr. s. auch Kuttner 1995.

39 S. dazu Winterling 2003: bes. 120-124.

40 Champlin 2003: 210-234. 
warum Domitian seine anschließenden Feldzüge gegen die Daker im Jahr 86 n. Chr. mit einem weiteren Triumph abschloss. Doch auch damals war noch längst kein endgültiger Sieg errungen, und so feierte er schließlich nach weiteren Feldzügen $89 \mathrm{n}$. Chr. einen doppelten Triumph über Germanen und Daker. Das hektische Streben nach rascher triumphaler Legitimation führte zu einer lange protrahierten Sequenz von immer wieder vorläufigen Initiations-Triumphen. Schließlich aber hatte auch Domitian das ,universale‘ Spektrum von Siegen im Norden und im Osten abgedeckt. Diese triumphale Manifestation schien ihm dann offenbar ausreichend für seine weitere Regierung, denn später, nach dem Krieg gegen die Sarmaten, verzichtete er auf den erwarteten Triumph und legte nur den Lorbeerkranz im Tempel des Iuppiter nieder. ${ }^{41}$

Schließlich nahm Traian bald nach Regierungsantritt den Krieg mit den Dakern wieder auf und beendete ihn schon im Jahr darauf $102 \mathrm{n}$. Chr. mit einem Triumph. Da auch hier wieder der Friede vorzeitig abgeschlossen wurde und sich nicht als haltbar erwies, unterwarf er Dakien in einem zweiten Krieg und beging 106 n. Chr. einen zweiten Triumph über denselben Gegner, mit dem er, ähnlich wie Domitian, seinen ersten Triumph gewissermaßen überholte. Ob Traian später den Krieg gegen die Parther, in dem er starb, mit einem Triumph abgeschlossen hätte, ist nicht zu erkennen. Die triumphale Rückkehr seiner Asche, die sein Nachfolger Hadrian veranstaltete, sagt nichts über Traians eigene Absichten aus. ${ }^{42}$

Seit Augustus und bis Traian erhielt das Ritual des Triumphzuges für die Kaiser einen neuen biographischen Stellenwert. Das republikanische Ideal der möglichst großen Zahl von drei oder mehr aufeinander folgenden Triumphen hatte seine Geltung verloren. Die Herrscher feierten zumeist nur ein Mal, allenfalls zwei Mal einander ergänzend, einen Triumph, möglichst am Beginn ihrer Laufbahn: entweder noch als vorgesehene Thronfolger oder bald nach Regierungsbeginn. Sie suchten zum Teil Gelegenheiten zu Feldzügen, auch wenn sie nicht unbedingt nötig schienen, feierten Triumphe, auch wenn der Gegner noch lange nicht besiegt war, und gestalteten ihre Siege und Triumphe als Demonstrationen der universalen Herrschaft über die ganze Welt aus. In dieser Form traten sie von Anbeginn und ein für alle Mal demonstrativ als immerwährende und ubiquitäre Sieger in Erscheinung. Spätere Kriegszüge konnten sie daher ausführenden Feldherren überlassen, eigene spätere Siege brauchten sie nicht mehr im ganz großen Staatsritus zu begehen.

Sieg wurde als Ergebnis einer dem Kaiser eigenen Sieghaftigkeit, das faktische Ereignis als Resultat einer dauerhaften Qualität erklärt. Der Triumphzug wurde in diesem Zusammenhang neu interpretiert: Er war nicht mehr in erster Linie ein Abschluss aller großen Feldzüge, sondern ein biographisches Initiationsritual des Kaisers, der sich dadurch vor oder zu Beginn seiner Regierung als fähig zur Übernahme dieser Aufgabe erwies.

41 Jones 1992: 126-159.

42 Strobel 2010: 255-260, 282-285. 
Wenn dann Hadrian und Antoninus Pius auf einen Krieg und Triumph zu Beginn ihrer Regierung verzichteten, so wurde der von ihnen eingeleitete Umschwung in der Reichspolitik, der Verzicht auf weitere Expansion, auch im ausbleibenden Ritual deutlich gemacht. Als dann Marc Aurel und Lucius Verus die Praxis wieder aufnahmen, geschah das stärker als zuvor unter den konkreten Vorgaben der Angriffe auf das Reich. Möglicherweise kam die Funktion des ,biographischen Rituals‘ dann mehr den aufkommenden Vota und Jubiläumsfeiern der Quinquennalia, Decennalia und Vicennalia zu. ${ }^{43}$

Aufschlussreich ist ein Vergleich mit dem Alten Ägypten. Erik Hornung hat gezeigt, dass jeder Pharao bald nach Beginn der Regierung einen Krieg gegen Fremdvölker in zwei polaren Weltgegenden, im Süden und Norden, führte. Das war, unabhängig davon, ob es nötig war oder nicht, eine rituelle Pflicht, mit der er die Ordnung der Welt aufrecht erhielt. An den Wänden der Tempel wurden diese ,rituellen‘ Kriege der Pharaonen in Reliefbildern in stereotypen Formen gefeiert, sei es in dem bekannten Schema des ,Niederschlagens der Feinde،, sei es in Schlachtszenen, in denen der Pharao auf dem Wagen eine dominierende Rolle spielt. Möglicherweise wurden solche Bilder zum Teil auch dann aufgestellt, wenn solche Kriegszüge nicht oder nur sehr symbolisch stattgefunden hatten. Es ist eine Auffassung von den iterativen religiös-ideologischen Aufgaben des Herrschers, die Hornung mit „Geschichte als Fest“ bezeichnet. $^{44}$

Die römische Auffassung geht längst nicht so weit in Richtung auf religiöse Ritualisierung der Rolle des Herrschers. Aber manche Züge werden durch den Vergleich erhellt. Das römische Kaisertum artikulierte sich und bestand, zu einem gewissen Grad, in rituellen Handlungen, die die soziale, politische und religiöse Ordnung des Reiches und der Welt aufrecht erhielten. Die Tempel für die Gottheiten dieser Ordnung hielten diese Ordnung auf Dauer visuell präsent und bewirkten als Orte der öffentlichen Kulte ihre Einbettung in das Leben der Gesellschaft. Der Kaiser war der oberste und in vieler Hinsicht einzige Realisator dieser traditionell vorgegebenen ideologischen Ordnung.

\section{,Ideologische‘ Herrschaft?}

Wenn man versucht, ein solches Konzept des römischen Kaisertums in Max Webers Kategorien der traditionalen, der legalen und der charismatischen Herrschaft einzuordnen, so gelingt das nicht leicht. Ich möchte daher zum Schluss die Frage aufwer-

43 Während der Berliner Tagung vorgeschlagen von Lukas de Blois. Vgl. in diesem Band S. 337-356.

44 Hornung 1966. 
fen, ob man nicht der Weber'schen Typologie einen vierten Typus zufügen sollte, den der ideologischen Herrschaft. ${ }^{45}$

Bis zu einem gewissen Punkt kann das römische Kaisertum, in Webers Sinn, teils als ,traditionale', teils als ,charismatische‘, in eingeschränktem Sinn sogar als ,legale‘ Herrschaft angesprochen werden. Alle drei Kategorien erfassen aber nicht die hier beschriebenen Aspekte.

,Legale“ Grundlagen hat das römische Kaisertum zunächst in der Bestellung des Princeps durch den Senat und die Einbettung seiner Herrschaft in die Praxis dieses Gremiums. Es ist offensichtlich, dass damit nur begrenzte Komponenten der Kaiserherrschaft benannt sind.

,Traditionale` Züge hat das römische Kaisertum in mindestens drei Aspekten: zum einen in seinen tendenziell ,patrimonialen' Machtstrukturen, in denen de facto immer wieder „ein (normalerweise) nach fester Erbregel bestimmter einzelner die Herrschaft ausübt“; zum zweiten in seiner Begründung auf ,republikanischen“ Traditionen, die der Herrschaft eine Art „Heiligkeit altüberkommener („von jeher bestehender") Ordnungen" vermitteln; und zum dritten, dazwischen vermittelnd, in der Praxis der reziproken Anerkennung und der konsensualen, pietätvollen Ehrung, mit der das Verhältnis zwischen Herrscher und Gemeinschaft realisiert wurde. Was dabei aber unterbewertet wird, ist die dominante Autonomie der ideologischen Leitbilder gegenüber den Personen der Herrscher, die durch ihre ,traditionale‘ Stellung als pater patriae wenig dagegen geschützt sind, an den Maßstäben dieses Kanons gemessen und vielfach verurteilt zu werden.

,Charismatische' Aspekte sind dem römischen Kaisertum insofern eigen, als seit Augustus eine überragende virtus, das heißt höchste persönliche Leistungen und einzigartige heldenhafte Fähigkeiten, die Grundlage für eine angestrebte affektive Hingabe an den Herrscher darstellten. Der Triumph ist das höchste Distinktiv dieser Einzigartigkeit. Doch damit ist wieder nicht das ganze Spektrum erfasst. Denn daneben waren für ihn andere Leitbilder verpflichtend, wie pietas, clementia, iustitia, fides, concordia und constantia, die alles andere als außergewöhnliche individuelle Eigenschaften darstellten, sondern kollektive Verhaltensideale waren, die in entsprechender Weise für breite Schichten der Gesellschaft Geltung hatten. Der Herrscher, der diese Leitbilder realisierte, zeichnete sich allenfalls durch breitere Verantwortung, aber nicht durch einzigartige Eigenschaften und Fähigkeiten aus.

Bekanntlich sind Webers Kategorien als Idealtypen konzipiert, die in der Realität nicht in Reinform auftreten, sondern Grundformen der politischen Legitimität bezeichnen, die in den historischen Herrschaftsordnungen in verschiedener Mischung realisiert sind. Die Herrschaft der römischen Kaiser lässt sich aber m.E. nicht ausreichend als Mischung von legaler, traditionaler und charismatischer Herrschaft beschreiben.

45 Weber 1922. Ich will auf diese Frage an anderer Stelle zurückkommen. 
Eine Herrschaft, die in einem wesentlichen Sinn als Realisierung eines vorgegebenen ideologischen Kanons verstanden wird, stellt einen eigenen Typus dar. Die Legitimität beruht im Wesentlichen auf den konsensual vorgegebenen ideologischen Leitbildern, die ihre Autonomie als kollektive Verhaltensmuster bewahren, weitgehend unabhängig von den individuellen Herrschern mit ihren legalen Einbindungen, traditionalen Herrschaftspositionen und/oder ihren charismatischen Führerqualitäten. Ideologische Herrschaft, wenn man sie so nennen darf, ist im römischen Kaisertum nicht in reiner Form vertreten, aber sie bedeutet einen wichtigen Faktor der Stabilität des Römischen Reiches.

\section{Bibliographie}

Alföldy, G. (1995): Eine Bauinschrift aus dem Colosseum. ZPE 109, 195-226.

Beard, M. (2007): The Roman Triumph. Cambridge.

Bergmann, M. (2000): Repräsentation. In: A. Borbein, T. Hölscher \& P. Zanker (Hrsg.): Klassische Archäologie. Eine Einführung. Berlin, 166-188.

Boschung, D. (1993): Die Bildnisse des Augustus. Berlin.

Bravi, A. (2012): Ornamenta Urbis. Opere d'arte greche negli spazi romani. Bari.

Camp, J. M. (1992): A Trophy from the Battle of Chaironeia of 86 BC. AJA 96, 443-455.

Castellvi, G., Nolla, J. M. \& Rodá, I. (1995): La identificación de los trofeos de Pompeyo en el Pireneo. JRA 8, 5-18.

Champlin, E. (2003): Nero. Cambridge.

Coarelli, F. (1985): Il Foro Romano II. Periodo repubblicano e augusteo. Roma.

Coarelli, F. (1988): Il Foro Boario. Roma.

Coarelli, F. (1997): Il Campo Marzio. Roma.

Dally, O. (2007): Das Bild des Kaisers in der Klassischen Archäologie, oder: Gab es einen Paradigmenwechsel nach 1968? JDAl 122, 223-256.

Delitz, H. (2009): Architektursoziologie. Bielefeld.

De Maria, S. (1988): Gli archi onorari di Roma e dell'Italia romana. Roma.

Fähndrich, S. (2005): Bogenmonumente in der römischen Kunst. Rahden.

Fears, J. R. (1981): The Theology of Victory at Rome: Approaches and Problems. In: ANRW II, 17.2, 736-826.

Freyberger, K. St. (2009): Das Forum Romanum. Spiegel der Stadtgeschichte des antiken Rom. Mainz.

Gros, P. (1976): Aurea templa: recherches sur l'architecture religieuse de Roma à l'époque d'Auguste. Paris.

Von Hesberg, H. \& Panciera, S. (1994): Das Mausoleum des Augustus. München.

Hoff, R. von den (2009): Caligula. Zur visuellen Repräsentation eines römischen Kaisers. AA, 239-263.

Hölkeskamp, K.-J. (1987/22011): Die Entstehung der Nobilität. Stuttgart.

Hölkeskamp, K.-J. (2012): Im Gewebe der Geschichte(n). Memoria, Monumente und ihre mythhistorische Vernetzung. Klio 94, 380-414.

Hölscher, T. (1967): Victoria Romana. Archäologische Untersuchungen zur Geschichte und Wesensart der römischen Siegesgöttin von den Anfängen bis zum Ende des 3. Jhs. n. Chr. Mainz.

Hölscher, T. (1978): Die Anfänge römischer Repräsentationskunst. MDAI(R) 85, 315-357. 
Hölscher, T. (1985): Denkmäler der Schlacht von Actium - Propaganda und Resonanz. Klio 67, 81-102.

Hölscher, T. (2000): Augustus und die Macht der Archäologie. In: A. Giovannini (Hrsg.): La révolution romaine après Ronald Syme: entretiens sur l'antiquité classique 46, 237-281.

Hölscher, T. (2001): Die Alten vor Augen. Politische Denkmäler und öffentliches Gedächtnis im republikanischen Rom. In: G. Melville (Hrsg.): Institutionalität und Symbolisierung. Verstetigungen kultureller Ordnungsmuster in Vergangenheit und Gegenwart. Köln, 183-211.

Hölscher, T. (2004): Provokation und Transgression als politischer Habitus in der späten römischen Republik. MDAI(R) 111, 83-104.

Hölscher, T. (2006a): The Transformation of Victory into Power: From Event to Structure. In: Sh. Dillon \& K. Welch (Hrsg.): Representations of War in Ancient Rome. Cambridge, 27-48.

Hölscher, T. (2006b): Macht, Raum und visuelle Wirkung: Auftritte römischer Kaiser in der Staatsarchitektur von Rom. In: J. Maran et al. (Hrsg.): Constructing Power. Architecture, Ideology and Social Practice / Konstruktion der Macht. Architektur, Ideologie und soziales Handeln. Hamburg, 185-201.

Hornung, E. (1966): Geschichte als Fest. Zwei Vorträge zum Geschichtsbild der frühen Menschheit. Darmstadt.

Humphrey, J. H. (1986): Roman Circuses. London.

Itgenshorst, T. (2005): Tota illa pompa. Der Triumph in der römischen Republik. Göttingen.

Itgenshorst, T. (2008): Der Princeps triumphiert nicht. Vom Verschwinden des Siegesrituals in augusteischer Zeit. In: H. Krasser, D. Pausch \& I. Petrovic (Hrsg.): Triplici invectus triumpho. Der römische Triumph in augusteischer Zeit. Stuttgart, 27-53.

Jones, B. W. (1992): The Emperor Domitian. London.

Köb, I. (2000): Rom - ein Stadtzentrum im Wandel. Untersuchungen zur Funktion und Nutzung des Forum Romanum und der Kaiserfora in der Kaiserzeit. Hamburg.

Kuttner, A. (1995): Dynasty and Empire in the Age of Augustus: The Case of the Boscoreale Cups. Berkeley.

La Rocca, E. (2001): La nuova imagine dei fori imperiali. MDAI(R) 108, 171-213.

La Rocca, E. (2008): La processione trionfale come spettacolo per il popolo romano. Trionfi antichi, spettacoli moderni. In: E. La Rocca \& St. Tortorella (Hrsg.): Trionfi Romani. Roma, 34-55.

Lefebvre, H. (1974): La production de l'espace. Paris.

Maderna-Lauter, C. (1988): Glyptik. In: Kaiser Augustus und die verlorene Republik. Katalog der Ausstellung Berlin. Mainz, 441-473.

Mayer, E. (2002): Rom ist dort, wo der Kaiser ist. Untersuchungen zu den Staatsdenkmälern des dezentralisierten Reiches von Diocletian bis zu Theodosius II. Mainz.

Muth, S. (2014): Historische Dimensionen des gebauten Raumes - Das Forum Romanum als Fallbeispiel. In: O. Dally et al. (Hrsg.): Medien der Geschichte. Berlin, 285-329.

Nedergaard, E. (1993): Arcus Augusti (a. 29 a.C.) und Arcus Augusti (a. 19 a.C.). In: E. M. Steinby (Hrsg.): Lexicon Topographicum Urbis Romae 1, 80-85.

Neudecker, R. (2010): The Forum of Augustus in Rome: Law and Order in Sacred Spaces. In: F. de Angelis (Hrsg.): Spaces of Justice in the Ancient World. Leiden and Boston, 161-188.

Noreña, C. F. (2011): Imperial Ideals in the Roman West: Representation, Circulation, Power. Cambridge.

Orlin, E. M. (1997): Temples, Religion and Politics in the Roman Republic. Leiden.

Papini, M. (2004): Antichi volti della repubblica. La ritrattistica in Italia centrale tra IV e II secolo a.C. Roma.

Pietilä-Castrén, L. (1987): Magnificentia publica: The Victory Monuments of the Roman Generals in the Era of the Punic Wars. Helsinki.

Reusser, C. (1993): Der Fidestempel auf dem Kapitol in Rom und seine Ausstattung. Roma. 
Schäfer, Th. (1998): Spolia et signa. Baupolitik und Reichskultur nach dem Parthererfolg des Augustus. Göttingen.

Schipporeit, S. (2008): Wege des Triumphes. Zum Verlauf der Triumphzüge im spätrepublikanischen und augusteischen Rom. In: H. Krasser, D. Pausch, I. Petrovic (Hrsg.): Triplici invectus triumpho. Der römische Triumph in augusteischer Zeit. Stuttgart, 95-136.

Schipporeit, S. (2010): Ritual und Herrschaft. Der jüdische Triumph der flavischen Kaiser. In: M. Meyer \& V. Gassner (Hrsg.): Standortbestimmung. Wien, 151-161.

Sehlmeyer, M. (1999): Stadtrömische Ehrenstatuen der republikanischen Zeit. Stuttgart.

Spannagel, M. (1999): Exemplaria Principis. Untersuchungen zu Entstehung und Ausstattung des Augustusforums. Heidelberg.

Stein-Hölkeskamp, E. \& Hölkeskamp, K.-J. (Hrsg.) (2006): Erinnerungsorte der Antike. Die römische Welt. München.

Strobel, K. (2010): Kaiser Traian. Eine Epoche der Weltgeschichte. Regensburg.

Timpe, D. (2011): Moderne Konzeptionen des Kaisertums. In: A. Winterling (Hrsg.): Zwischen Strukturgeschichte und Biographie. München, 127-159.

Torelli, M. (1968): Il donario di Fulvio Flacco nell'area sacra di S. Omobono. Quaderni dell'Istituto di Topografia antica 5, 71-75.

Torelli, M. (1982): Typology and Structure of Roman Historical Reliefs. Ann Arbor.

Walter, U. (2004): Memoria und res publica. Zur Geschichtskultur im republikanischen Rom. Frankfurt/M.

Weber, M. (1922): Die drei reinen Typen der legitimen Herrschaft. Preußische Jahrbücher 187, 1-12.

Winterling, A. (2003): Caligula. Eine Biographie. München.

Zachos, K. L. (2001): To mnemeio tou Oktabianou Augoustou ste Nikopoli. Athenai.

Zanker, P. (1970): Das Trajansforum in Rom. AA, 499-544.

Zanker, P. (1972): Forum Romanum. Die Neugestaltung durch Augustus. Tübingen.

Zanker, P. (2004): Die Apotheose der römischen Kaiser. Ritual und städtische Bühne. München.

Ziolkowski, A. (1992): The Temples of Mid-Republican Rome and their Historical and Topographical Context. Rom. 